\title{
MALACATES PREHISPÁNICOS CON FIGURAS HUMANAS EN RELIEVE
}

HASSO VON WINNING

Entre los numerosos estudios sobre los malacates prehispánicos de México que tratan sobre su distribución geográfica y temporal, y sobre la ornamentación de tales implementos para hilar, se nota la escasez de comentarios sobre aquellos ejemplares decorados con figuras humanas. Una gran parte de la enorme cantidad de malacates encontrados en la Cuenca de México -Horcasitas y Ford (1961:137) hablan de millares y de "varios millones todavía enterrados en tierras mexicanas"- están grabados o incisos con diseños geométricos. Otros representan animales (insectos, aves, monos, ranas y cuadrúpedos) o flores, pero raras veces figuras humanas.

El objeto de este estudio es presentar una colección de 28 malacates cuyos relieves representan caras humanas ofiguras enteras, grabadas artísticamente con una finura extraordinaria. ${ }^{1}$ En lo particular llaman la atención los diferentes rasgos faciales que sugieren que puede tratarse de personajes históricos, cuyas posiciones jerárquicas quedan expresadas por los tipos de tocados.

Los malacates en cuestión proceden en su mayoría de Culhuacan; los demás, de sitios en el Valle de México. Fueron adquiridos por el autor entre 1939 y 1948, cuando todavía era posible encontrar "tepalcates" en las milpas o comprárselos a los campesinos antes de la expansión urbana del Distrito Federal.

Aproximadamente la mitad son ejemplares pequeños y livianos, hasta 3 cm de diámetro; los demás miden hasta $5 \mathrm{~cm}$. Por lo general se considera que los malacates pequeños sirvieron para hilar el algodón y los de mayor tamaño para fibras de maguey (ixtle). Sin embargo, malacates de tamaño menor pudieron haberse usado para hilar fibras de ixtle más finas (Raymond 1984:219), y asimismo los de mayor tamaño también para el algodón (García Cook y Merino 1974:33). El maguey se cultiva en el altiplano y el algodón era

\footnotetext{
${ }^{1}$ Agradezco a la doctora Nelly Gutiérrez Solana su valiosa ayuda en la revisión del texto y de los dibujos, asegurando la fiel reproducción de los relieves. Igualmente doy las gracias al Dr. Thomas Barthel por sus consejos y su contribución sustancial a este trabajo.
} 
importado de la región del Golfo de México, del Valle de Morelos, Guerrero, y del sur de Puebla. En Tlaxcala se hilaba el ixtle desde 300 a. C. y el algodón desde 100 d. C. (García Cook y Merino 1974:33-34).

De la Huasteca se conocen malacates con decoración en relieve de extraordinaria finura gracias a los estudios e ilustraciones de Cecilia Seler (1916:98-135) y Gordon Ekholm (1944:459-467). Entre ellos solamente se encuentran seis figuras humanas y tres calaveras; los demás diseños representan animales y dibujos geométricos. Algunos de los malacates huastecos llevan pintura negra de chapopote en su parte plana, lo que facilita la identificación de aquellos ejemplares localizados en la Cuenca de México, debido al comercio entre las dos regiones.

En las dos obras sobre malacates de la Cuenca de México que contienen un mayor número de ilustraciones, se encuentran diez representaciones humanas que corresponden a tipos a los cuales nos referimos en este trabajo. En una obra póstuma de Jorge Enciso (1971) se ilustran 300 diseños. Lamentablemente dan una imagen burda de la composición de los relieves porque muchos detalles importantes fueron sustituidos por gruesas líneas negras (Fig. 8). En efecto, los dibujos esquematizados no son copias fieles de los artefactos originales y, desgraciadamente, resultan inservibles para un estudio iconográfico. ${ }^{2}$ Lo mismo sucede con los 90 dibujos, todos exactamente del mismo tamaño y muy similares a los de Enciso, que acompañan elbreve pero informativo artículo de Fernando Horcasitas y los esposos Ford (1961:137-150). Se puede deducir, sin embargo, que deben existir por lo menos dos, o probablemente más, malacates con las mismas representaciones de figuras humanas, lo que nos lleva a la cuestión de su manufactura.

Los malacates de cerámica fueron hechos en moldes y perforados en el centro antes de la cochura (Fig. 6). En casi todos los ejemplares que presentamos se nota que muchos detalles han sido grabados minuciosamente con un instrumento muy agudo, después de haber sido removido el malacate de su molde. En algunos casos el grabado es tan fino que requiere un lente de aumento para poder reconocer los elementos iconográficos y comprender su significado. Sorprende el hecho de que se conocen muy pocos moldes. Posiblemente fueron destruidos, lo que sucedió también con los moldes de la cerámica en relieve del centro de Veracruz (Río Blanco), pues hasta la fecha no se han encontrado ejemplares de los mismos.

${ }^{2}$ Lo mismo se puede decir de la obra de Jorge Enciso, Sellos del antiguo México, México, 1947, con dibujos del autor. Aparentemente el propósito fue presentar y hacer accesible una sinopsis sobre la gran variedad de diseños decorativos prehispánicos, como lo revelan los sellos, que pudiera servir como fuente de inspiración para la creciente industria platera en el Taxco de aquel tiempo. 
En tiempos prehispánicos la tarea de hilar correspondía a las mujeres, como lo demuestran el Códice Mendocino y el Vindobonensis (Fig. 1); por ello se les mostraba a las niñas recién nacidas pequeños husos y malacates en miniatura cuando eran bautizadas por la partera.

\section{Descripciones}

\section{Malacates con rostros humanos vistos de frente (Fig. $2 a$ y b)}

Ambos ejemplares parecen representar una máscara sobrepuesta a un individuo cuya boca se percibe entre los dientes rectangulares. Las orejeras se componen de discos con colgajos tubulares. Llama la atención en cada uno que la nariz triangular se extiende más arriba del nivel de los ojos. Este detalle se puede comparar con la cara frontal en el gran tocado de las estelas 2 y 3 de Tula (Catálogo Tula, núms. 99 y 100) (Fig. 7a yb). Bajo el gran penacho dela estela 2 se encuentra un pájaro(¿búho?) y la cara del personaje principal, que es la de un guerrero, está rehundida dentro de un marco. Igualmente, la cara del guerrero de la estela 3 está rehundida y las orejeras son del mismo tipo que las de los malacates.

Ambos malacates fueron adquiridos en Huexotla, sitio que estuvo ligado con el señorío de Acolhuacan (Texcoco). El desarrollo histórico-arqueológico, basado en los restos arquitectónicos, ahora parcialmente reconstruidos, y en la cerámica azteca, se divide en tres épocas. La primera, con cerámica "Azteca temprana", abarca el periodo de 1150 a 1350 aproximadamente. La duración de la segunda época está marcada por cerámica "Azteca tardía" y se estima entre 1350 y 1515. La tercera, de 1515 hasta la Conquista, refleja el dominio de Tenochtitlan (García García 1987:99-101).

Tomando en cuenta la presencia de rasgos toltecas y la influencia de Tula en Huexotla aun después de la caída de la capital tolteca en 1168 (o en 1175, según Davies, 1980:55), suponemos que los dos malacaies corresponden al primer periodo de Huexotla, o sea al Posclásico temprano, entre 1150 y 1350. El diseño del mascarón recuerda las lápidas de Tula con una figura zoomorfa por cuya boca asoma un rostro humano (Cfr. Catálogo Tula, Figs. 133 y 134).

\section{Malacates con caras estilizadas con dientes puntiagudos (Fig 2c-e)}

Se distinguen del grupo mencionado arriba por sus dientes triangulares vistos de frente. Las grandes volutas supraorbitales, las orejeras (semejantes 
al glifo maya T61 o T62) y los colgajos de la nariz (Fig 2d, e) son elementos que aparecen en la cerámica clásica tardía del centro de Veracruz (Río Blanco) (Von Winning 1984). José Luis Franco reproduce, en una pequeña fotografía, un malacate procedente de la Ciudad de México, casi idéntico al de la figura $2 \mathrm{~d}$, y el autor comenta el parecido con los malacates huastecos que son artísticamente superiores (Franco 1956:205, lám. III:27). En la obra de Enciso (1971:48) se incluye un dibujo esquemático de este tipo de malacates, pero no se da ningún comentario (Fig, 8a).

Probablemente este grupo de malacates representa el mascarón de un felino. Me parece dudoso que hayan sido hechos en el periodo Azteca III como lo sugiere Franco. La composición recuerda más bien el estilo del final del Clásico de la Costa del Golfo (Tampico o Río Blanco).

\section{Malacates con dos, tres o cuatro cabezas diferentes, en perfil (Fig. 3a-i)}

Se notan las siguientes particularidades:

a) Las caras miran hacia la periferia (Fig. 3a, b) o hacia el centro (Fig. 3c-i).

b) En cada par la cabeza opuesta está volteada 180 grados, lo que concuerda con el sentido rotatorio del malacate

c) La forma del ojo, de la nariz y de la boca son diferentes en cada rostro, lo que sugiere que se trata de retratos de verdaderos personajes históricos. Su alto rango se manifiesta en los tocados con grandes penachos. La boca del personaje A en la figura $3 a$ indica que es un anciano.

d) Las "coronas" también son diferentes y constan de cuentas circulares (Fig, 3a, c, g, h) o rectangulares (Fig. 3e-h). Una banda de mosaicos (Fig. 3d, $\mathrm{e}, \mathrm{i})$ es el adorno típico de los guerreros toltecas en los relieves de las pilastras y en los atlantes monumentales de Tula (Fig. 9).

e) Algunos individuos lievan narigueras tubulares, adorno típico tolteca o del Posclásico temprano. Sus formas varían debido a la dificultad de representarlas frontalmente sobre los rostros de perfil y además en un espacio muy reducido.

f) Signos simbólicos. Ambos malacates de las figuras 3a y b despliegan el mismo signo detrás del tocado del personaje A y B. Este signo representa un caracol, tal como ocurre en representaciones de ríos o lagos. También ocurre en el borde inferior de la falda de la Cihuacoatl, diosa de la tierra y patrona de Culhuacan. Los círculos concéntricos o protuberancias que aparecen asimismo no tienen necesariamente un significado calendárico.

g) En la figura 3d se representa un individuo con indumentaria tolteca (la corona de mosaicos con el gran penacho y la nariguera tubular), pero el 
individuo opuesto (B) tiene la parte inferior de la cara estilizada, lo que posiblemente indica una máscara. ${ }^{3}$

¿Qué significado tienen estas representaciones? Como ya asentamos, los relieves de estos malacates fueron elaborados muy detalladamente y están muy bien conservados. No se trata probablemente de objetos de uso diario sino asociados al culto o a ofrendas funerarias. La diversidad en las fisonomías y en los tocados nos hace pensar que se trata de gobernantes que reinaban en Culhuacan y en Huexotla antes del surgimiento de Tenochtitlan.

Según las fuentes históricas, dos o tres y hasta cuatro gobernadores participaban en el poder simultáneamente, de los cuales uno funcionaba como primus inter pares. Esta forma de gobierno existía en Tula y se continuó en aquellas ciudades con una fuerte tradición tolteca; entre ellas figuraba también Culhuacan, como lo expone detalladamente Davies (1977:293ss; 1980:37-41, 185ss, 315, 358).

Entre los nueve malacates con dos o tres rostros diferentes, ocho provienen de Culhuacan, el otro de Huexotla. La lista de los reyes de Culhuacan incluye 39 , para los cuales se mencionan 14 nombres diferentes (Davies 1980:358). Pero no es posible determinar cuáles gobernantes fueron esculpidos en los malacates ya que no incluyen signos onomásticos.

Antes de comentar sobre los malacates con dos cabezas o figuras idénticas, nos referimos al malacate con cuatro personajes en cuatro secciones (Fig. 3i). La división en cuatro secciones está acentuada por medio de cuatro barras paralelas. Cada persona tiene una "corona" de mosaico. Dos individuos opuestos, A y D, están sentados y sostienen una lanza o báculo. Contrastan con B y C, que aparentemente están ataviados con una capa decorada con puntas de flecha. Sin embargo, que yo sepa, no existe documentación sobre el uso de este tipo de atavío y es más probable que se trate de la representación de un jefe con una "casa" donde se guardan armas, o sea de un tlacochcalco yaotl, "el guerrero de la casa de los dardos" (Seier GA II 1963:495-498).

Además, T. Barthel sugiere que los atributos de $\mathrm{B}$ y $\mathrm{C}$ parecen indicar la filiación étnica de los cuatro personajes como jefes (por su tocado tolteca) de los tlacochcalca que habían venido del norte, estableciéndose en Chalco. Allí construyeron un templo a su dios titular Nappatecutli, el "cuatro veces señor" (Brundage 1979:87-88). Su jurisdicción como "señor de los cuatro

\footnotetext{
${ }^{3}$ La doctora Nelly Gutiérrez Solana propone que se puede tratar de un dios con el labio extendido (long snout god). En tal caso sería un individuo con máscara bucal como se observa en la cerámica de Río Blanco y en las figuras clásicas tardías de El Zapotal, Veracruz ( $C f$ r. Nelly Gutiérrez Solana y Susan K. Hamilton, La escultura en terracote de El Zapotal, Veracruz, UNAM, 1977, Figs. 47 y 60 con las cabezas laterales en la escultura del Dios de la Muerte). Entonces tendríamos otra indicación de la influencia de Veracruz en la Cuenca de México.
} 
rumbos" está expresada en el malacate por los cuatro sectores delimitados claramente entre sí por cuatro barras.

En la obra de Enciso (1971:28) se reproduce un dibujo semejante pero mucho menos detallado y sin comentario (Fig. 8d).

4. Malacates con dos cabezas humanas similares y con diseños naturalistas (Fig. 4a-c)

Fig. 4a. Tres diseños similares están distribuidos en seis sectores de tal manera que los pares se encuentran en posiciones opuestas. Tal diposición recuerda las figuras opuestas en la cerámica policroma maya del Clásico (re-entrant figures). Una de las caras lleva una nariguera tubular, señal que permite fechar al malacate en el Posclásico. Los diseños curvilíneos parecen ser plantas.

Fig. $4 b, c y d$. En estos tres malacates los rostros con labios extendidos son muy semejantes. En el $4 \mathrm{~b}$ la cara tiene un adorno de plumas detrás de la cabeza, mientras las cabezas de 4c y 4d están unidas con un caracol (tecciztli), lo que hace pensar en Tecciztecatl, dios del caracol marino, quien en general se considera como un dios lunar (Fig. 10).

El caracol es un símbolo de nacimientos, según el intérprete del Códice Telleriano-Remensis 13: "así como sale del hueso el caracol, así sale el hombre del vientre de su madre" (Spranz 1964:138).

Sin embargo, Tecciztecatl aparece en diversas formas en los códices y cuando lleva el caracol lo tiene puesto en la frente (e.g. Códice Borgia 11). Thompson duda que Tecciztecatl sea un dios lunar porque carece de los atributos lunares. Entre los mayas el viejo dios Mam porta un gran caracol en la espalda (Thompson 1960:12, Fig. 21:1-7); es un dios terrestre y se dice que causa terremotos cuando se mueve en el interior de la tierra.

En el altiplano de México la concha marina es un símbolo constante de Tepeyollotli, "corazón del monte", el dios del interior de la tierra, quien aparece en su aspecto de jaguar. Pensamos, por lo tanto, que en los malacates de la figura $4 c$ y d no se trata de Tecciztecatl sino de Tepeyollotli.

Como ya mencionamos, los rostros de $4 \mathrm{~b}$ son semejantes a los de Tepeyollotli con la concha. En dicho malacate, cuyo diseño está dividido en cuatro secciones - Tepeyollotli es dios de oeste-, aparece asimismo un diseño ovalado cuyo interior despliega un triángulo con pequeños huecos internos. Una comparación con la ilustración de las siete cuevas de Chicomoztoc en la Historia Tolteca Chichimeca (Kirchhoff 1976, fol. 16r) permite identificar al diseño del malacate $4 \mathrm{~b}$ como una cueva, aunque no necesariamente como Chicomoztoc (Fig. 12). Pero tal identificación con- 
cuerda con las dos caras acompañantes de Tepeyollotli en su aspecto de dios de las cuevas.

Ofreciendo una interpretación alternativa de los malacates con caracoles (Fig. 4c y d), T. Barthel llama la atención al primer capítulo del Códice Borgia. Tecciztli (caracol) ocurre en Borgia 4 arriba en la columna 21 y corresponde a "(8) atl" y en Borgia 8 abajo, en la columna 47 "(8) quiauitl" (Fig. 10). Es decir, se contrastan, como en los malacates, un tecciztli superior con otro inferior, lo que indica una disposición intencional. En el capítulo de las trecenas " 8 acatl" (Borgia 63a) corresponde a la trecena 1 malinalli bajo el patrocinio de la diosa Chantico, y 8 quiauitl en la trecena 1 malinalli (Borgia 68a) con la diosa Mayauel, cuya función como "primera madre" se califica mediante un pez (=progenie). De esta manera, Barthel relaciona el caracol (Tecciztli), el símbolo de nacimiento, con el concepto de feminidad inherente en la función rotativa de los malacates. Trataremos sobre dicho concepto más adelante.

\section{Malacates con figuras humanas de cuerpo entero (Fig. 5a-h)}

Fig. 5a. Sobre un pequeño malacate está extendido un cuerpo humano (¿femenino?) sobre la espalda. Extiende los brazos y las piernas simétricamente como una rana. Tal postura ("Hocker") se observa también en los códices aztecas y mixtecos, por ejemplo, en las representaciones del monstruo de la tierra en la sección del tonalamatl del Códice Borbónico. La persona en el malacate aparece desnuda y no tiene atributos.

Fig. 5b. El guante en la mano derecha del individuo y las formas semiesféricas indican que se trata de un jugador de pelota. La reproducción de Enciso (1971:50) muestra un individuo en la misma postura pero sin el guante (Fig. 8e). La representación de un jugador de pelota en un malacate evoca el término náhuatl tlachtemalacall, que designa el anillo de piedra en las construcciones arquitectónicas (ilachco).

Fig. 5c. Un personaje con "alas" o plumas en los brazos y un elemento para proteger la rodilla es un participante en el ritual del juego de pelota. $\mathrm{El}$ mismo individuo aparece en los malacates publicados por Horcasitas y Ford (1961, lám. I:1, de Tezcoco) y Enciso (1971:50) con un cojinete en ambas rodillas (Fig. $8 \mathrm{f}, \mathrm{g}$ ). La representación del personaje alado se debe a las influencias de costumbres rituales asociadas con el juego de pelota del centro de Veracruz. Individuos alados se encuentran en el contexto de escenas narrativas en algunas de las vasijas decoradas en relieve de la región de Río Blanco, Veracruz, que datan del final del Clásico (c. 700-900 d.C.) (Fig. 13). 
La mayoría de las escenas se refieren al juego de pelota que en Veracruz tenía gran importancia (von Winning 1971, Figs. 1, 2 y 5). También el paño de cadera cuadriculado en el malacate, que viste el personaje, es típico de los atavíos de la costa del Golfo (Tajín, Río Blanco). La cabeza zoomorfa en el centro puede ser una serpiente con su lengua bífida.

Fig. 5d. Es el único malacate de la colección cuyo diseño fue hecho con incisiones antes de la cochura y no en relieve. El individuo parece femenino porque las piernas están cubiertas con una enagua y sólo los pies, sin sandalias, son visibles, pero si la cinta ancha que se extiende delante es parte del maxtlatl, entonces el personaje sería masculino.

Fig. $5 e$. Un personaje con yelmo de águila trata de sacar una lanza que atraviesa su pierna izquierda. Otra flecha ha pasado por su pie derecho. Existe un duplicado de este malacate, lo que indica que ambos ejemplares fueron hechos con el mismo molde. Un tercer ejemplar semejante fue publicado por Enciso (1971:28) (Fig. 8h).

En mi discusión sobre el significado de este tema, en un artículo anterior, había concluido que el guerrero herido simboliza los efectos dañinos de los rayos del planeta Venus al aparecer en el horizonte después de su conjunción inferior (von Winning 1975:124-129). En las escenas del Códice Borgia 53-54 y también en el Códice Dresden 46-50 aparece el dios Tlahuizcalpantecutli, la estrella matutina, en diversos aspectos y arrojando flechas.

En Borgia 54 hiere la pierna de Tezcatlipoca, derramando sangre; Seler (1963, II:113-128) y Thompson (1972), en su comentario sobre el Códice Dresden, han aclarado estas escenas brillantemente. De acuerdo con la temática de la decoración y el hecho de que proceden de Culhuacan, se puede fechar ambos malacates probablemente en el siglo xIII.

Fig. 5f. Representa un guerrero con la máscara de un águila. Sostiene un par de palos cuya parte superior está quebrada y da vuelta. El brazo izquierdo parece estar cubierto con una manga acojinada al estilo de los guerreros toltecas (Cfr. Catálogo Tula, Pilar III de Tula, Fig. 70a) y en la mano sostiene un atlatl. Probablemente se trata de un cabailero águila.

Fig. 5g. Franco (1956:202-203, lám. I) ilustra varios malacates del complejo Tula-Mazapan, cuyos diseños -según aparecen en la lámina citada- se componen de elementos aislados y separados por amplios espacios. Semejante estilización se observa en el malacate $5 \mathrm{~g}$. El individuo está sentado en un banco, lleva máscara de un cozcaquauhtli ("zopilote real") y en cada mano tiene una sonaja de diferente diseño. Debajo del pico se ve un chalchihuite con un pendiente que se asemeja al oyohualli, el signo de los dioses de la música y de la danza y que en los códices cuelga de la oreja humana del cozcaquauhtii. El anillo en el ojo y el cabello despeluznado también son 
características del zopilote. La figura posiblemente representa a Xochipilli, dios de la danza y la música, quien aparece en el Códice Magliabechi 35 con una máscara de ave.

Fig. 5h. Dos individuos, con sólo pequeñas diferencias en la cara y en la forma del paño de cadera, tienen el mismo tocado. Parecen estar sentados y apuntan con un dedo extendido. Enciso (1971:28) publica una escena similar (Fig. 8j).

En resumen, el resultado de nuestras interpretaciones da las conclusiones siguientes: los malacates con dos o tres rostros individualizados y grabados en un estilo relacionado con el arte escultórico tolteca conmemoran posiblemente personajes históricos de filiación ancestral tolteca. Por lo tanto, la iconografía revela temas sociopolíticos.

Por otro lado, los malacates, inclusive aquellos con diseños zoomorfos o geométricos, simbolizan, por su forma y función rotativa, un concepto ritualreligioso. Su significado merece el siguiente comentario basado en las investigaciones de Thomas Barthel y discutido con el autor.

Empezamos con la pregunta: ¿qué concepción simbólica tenía un malacatl para un nahuatlaco, aparte de su función utilitaria para las hilanderas? La explicación nos la da Sahagún en su capítulo de "Algunos zazanjles de los muchos que usa esta gente mexicana: que son como los que cosa y cosa de nuestra lengua". Pregunta: "¿Qué cosa y cosa que en un día se empreña? Es el huso con la mazorca." "¿Qué son aquellas cosas que, en su sitio de bailar, empreñan? Son los husos." (El "sitio de bailar" se refiere al pequeño cajete que se usa para soportar la rueca, de modo que el huso parece bailar, dando vueltas) (Florentine Codex 1969, Bk.6:239-240).

Por consiguiente, entre la gente común se pensaba que el huso con su malacate causa el embarazo, pues la rueca "engorda" durante el proceso de hilar. La deidad patrona de los partos y nacimientos era la diosa Tlazolteotl, a quien se representa en los códices con una venda de algodón sin hilaĩ eñ el tocado y uno o dos malacates o husos (Fig. 11). Tanto el Borgia como el Laud contienen imágenes de la diosa con sus malacates cuya distribución se relaciona con las fases lunares.

En el Códice Laud aparecen cuatro mujeres con malacates (husos):

1) Laud 15 (Kingsborough): Tlazolteotl tiene en la cabeza una rueca con malacate blanco, es decir, todavía no ha empezado a hilar. Está sentada en una encrucijada (=aspecto negativo) en la cueva del suroeste. El signo ollin (abajo, derecha) indica movimiento correspondiente al uso del malacate.

2) Laud 30a: Tlazolteotl en el lugar donde se taladra el fuego sobre la xiuhcoatl; dicha actividad es una tarea exclusivamente masculina y representa un tema de procreación. El movimiento de los maderos (mamalhuaztli) de un 
ladoa otro es comparable al de un huso. El malacate es de color rojo y la rueca está llena de hilo.

3) Laud 32a. Tlazolteotl se encuentra en la región de los vientos (nótense las cabezas de Ehecatl). El malacate en el tocado es rojo y el que tiene en la mano es azul (Fig 11).

4) Laud 42. Tlazolteotl está parada enfrente de las fauces de un monstruo que se prepara para tragar a un recién nacido; ella tiene emblemas mortuorios en su falda. El malacate en el tocado es azul.

De acuerdo con este orden se obtienen las siguientes fases lunares contrastantes: 15 vs. 30 (luna llena vs. luna nueva) vs. $(32+42)=74$ (nuevamente luna llena). El cambio en el movimiento entre las posiciones lunares (la luna nueva del oeste al este, luna llena del este al oeste) es comparable con el movimiento de un lado a otro de un malacate (Barthel 1972, 1973, 1975).

En el Códice Borgia, Tlazolteotl está relacionada con malacates (husos) en nueve cuadros: cuatro veces con dos husos: Borgia 12a - $16 \mathrm{a}-55 \mathrm{c}-59 \mathrm{~b}$ ( 2 husos en la vasija). En Borgia 14a, 23a, 50b-m, 63b y 74a la diosa tiene solamente un huso en el tocado. Calculando los valores calendáricos resulta:

$14+16(=30)$ y $55+63(=118)=148=5$ lunaciones en su orden correcto.

$23+50(=73)+74=147=5$ lunaciones (cambio de fases: 73 vs. 74$)$.

En los cuatro casos en que las fases lunares siguen en su propio orden aparecen 6 husos y siempre se trata de una madre (o metafóricamente de una guerrera) acompañada de una serpiente.

En los tres casos del cambio de fases lunares se encuentran 3 husos que temáticamente se refieren al casamiento y a la concepción. Estas 7 apariciones con 9 husos suman 295 (el total de las páginas), lo que equivale a 10 meses sinódicos o sea el periodo máximo de embarazo.

Los 7 casos con $6+3=9$ husos $=10$ lunaciones se prestan, basándose en la "concepción" ilustrada en Borgia 74, a un arreglo en forma de encrucijada:

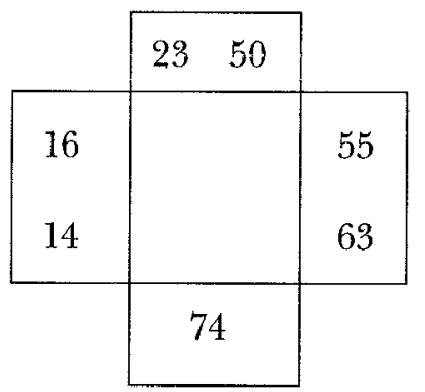

Si añadimos la temática correspondiente, resulta el siguiente cuadro: 


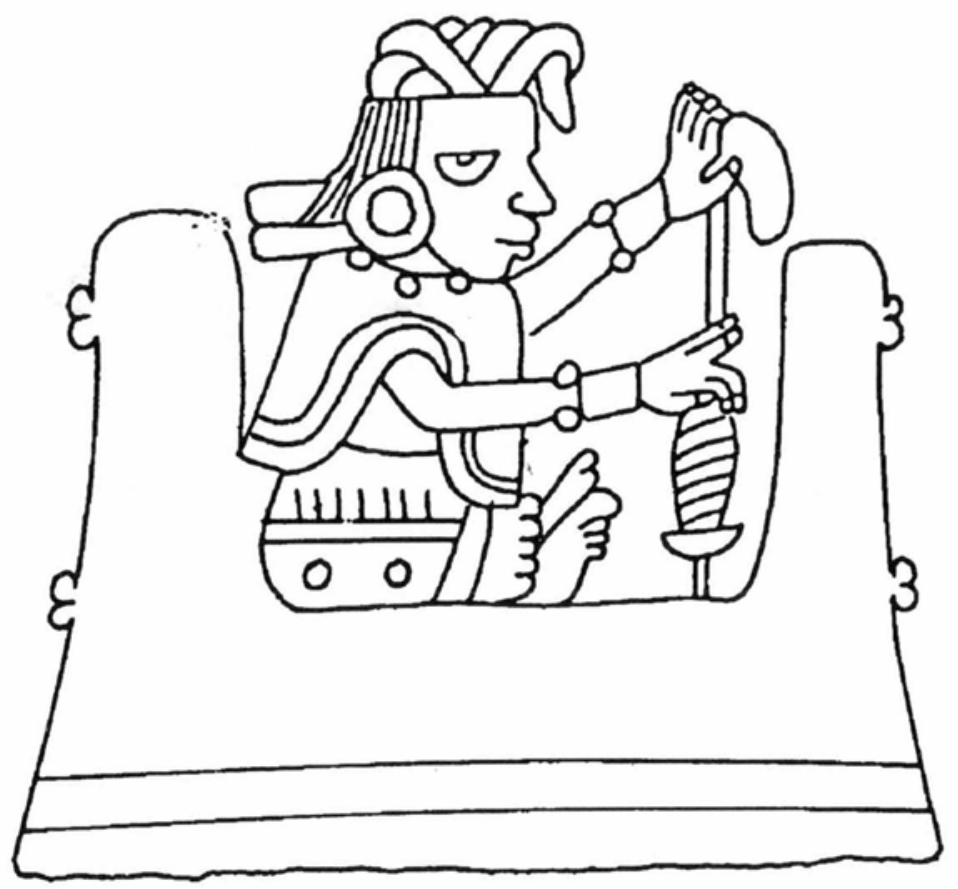

Fig. 1 Mujer hilando, Códice Vindobonensis 9.

Fig. 2 Malacates con rostros estilizados, vistos de frente

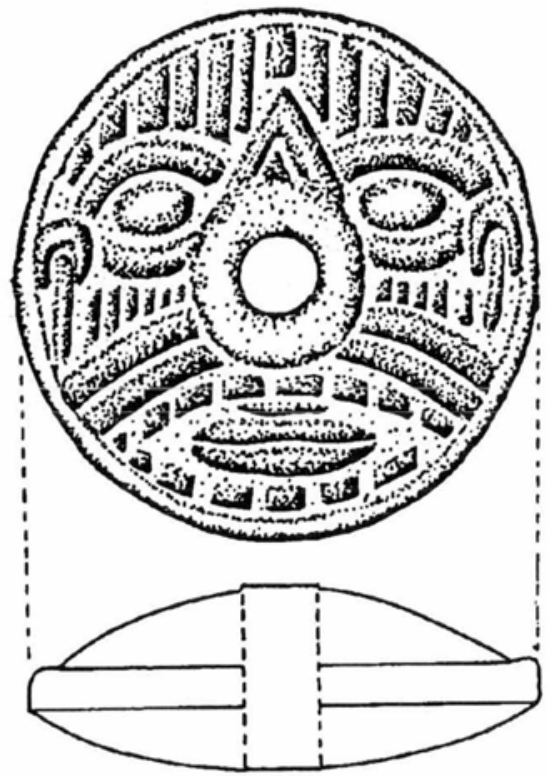

a. $2.8 \mathrm{~cm}$ diam., $11 \mathrm{~mm}$ altura, café claro. Huexotla. 


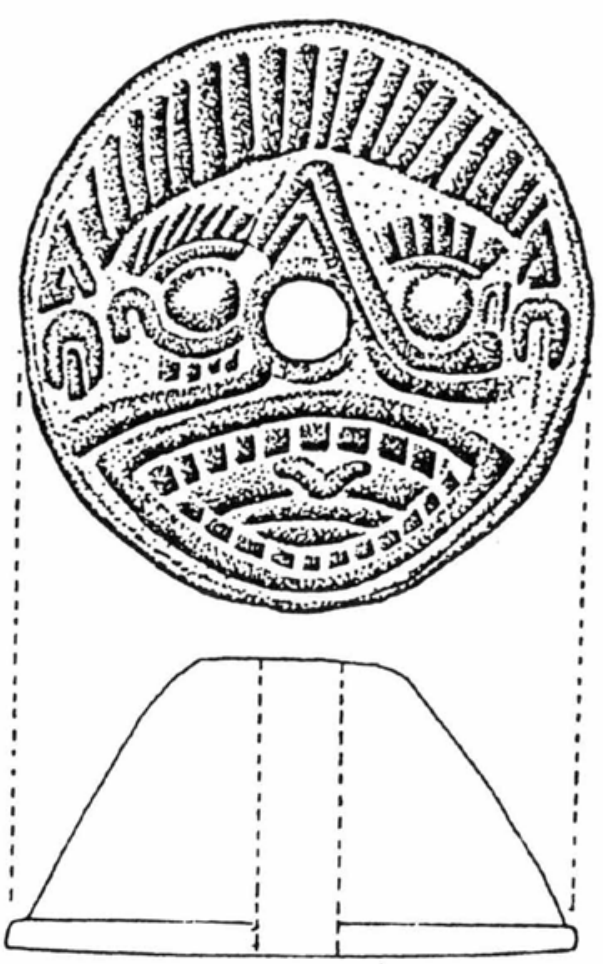

b. $2.6 \mathrm{~cm}$ diam., $11 \mathrm{~mm}$ altura, café oscuro. Huexotla.

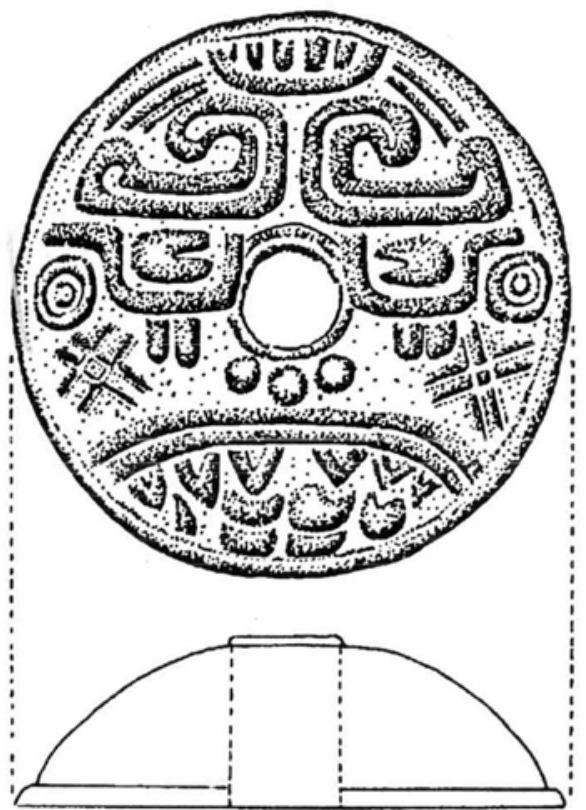

c. $4.5 \mathrm{~cm}$ diam., $1.3 \mathrm{~cm}$ altura, café claro, Valle de México. 


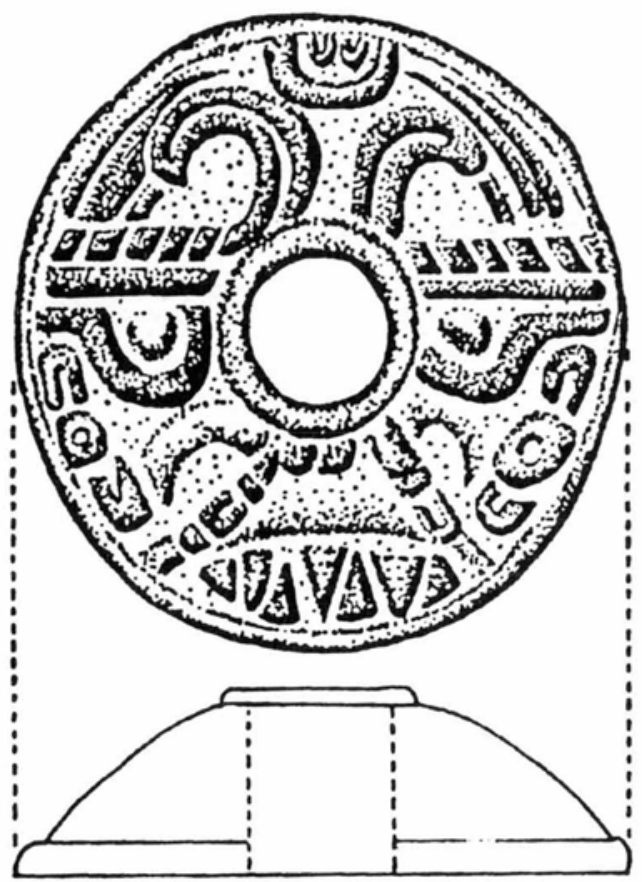

d. $4.5 \mathrm{~cm}$ diam., $1.3 \mathrm{~cm}$ altura, gris, Valle de México.

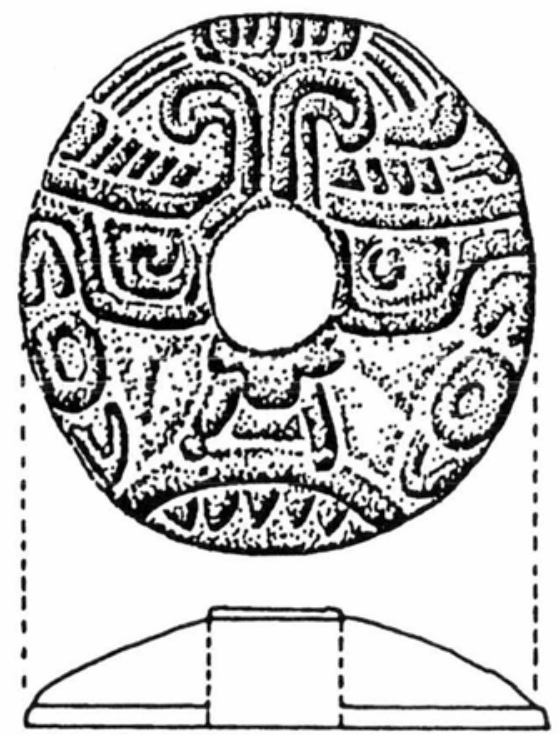

e. $2.5 \mathrm{~cm}$ diam., $7 \mathrm{~mm}$ altura, café oscuro, Culhuacan. 
Fig. 3 Malacates con 2, 3 o 4 rostros diferentes en perfil.

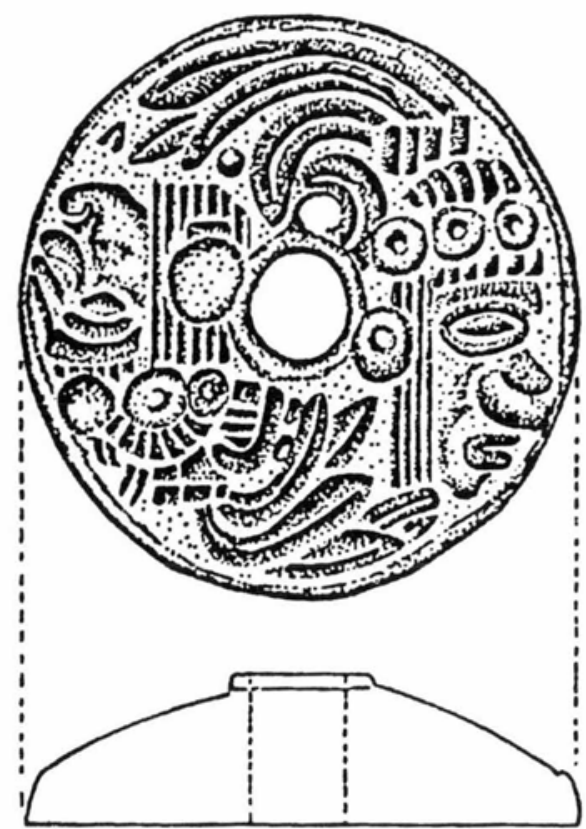

a. 3.4. $\mathrm{cm}$ diam., $8 \mathrm{~mm}$. altura, café con manchas negras, Culhuacan.

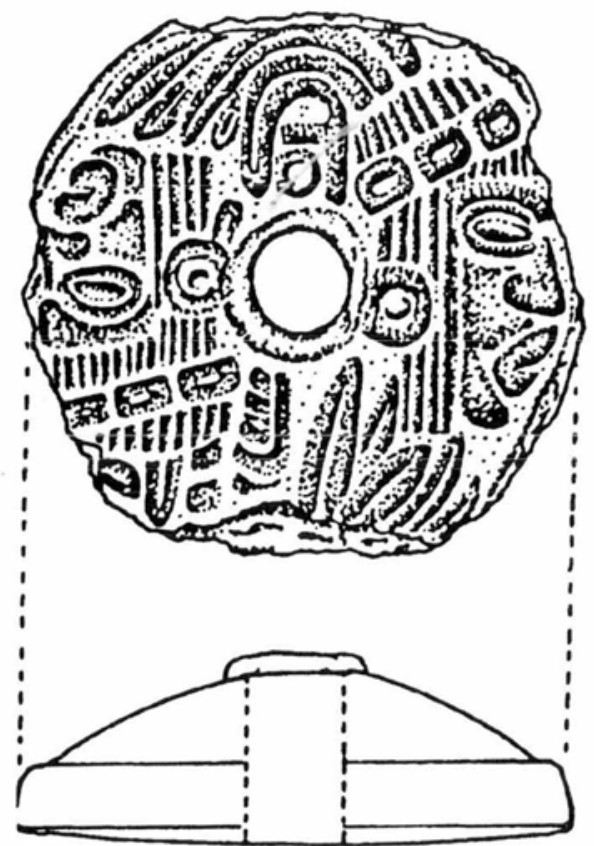

b. $2.9 \mathrm{~cm}$ diam., $9 \mathrm{~mm}$ altura, café bruñido, Huexotla. 


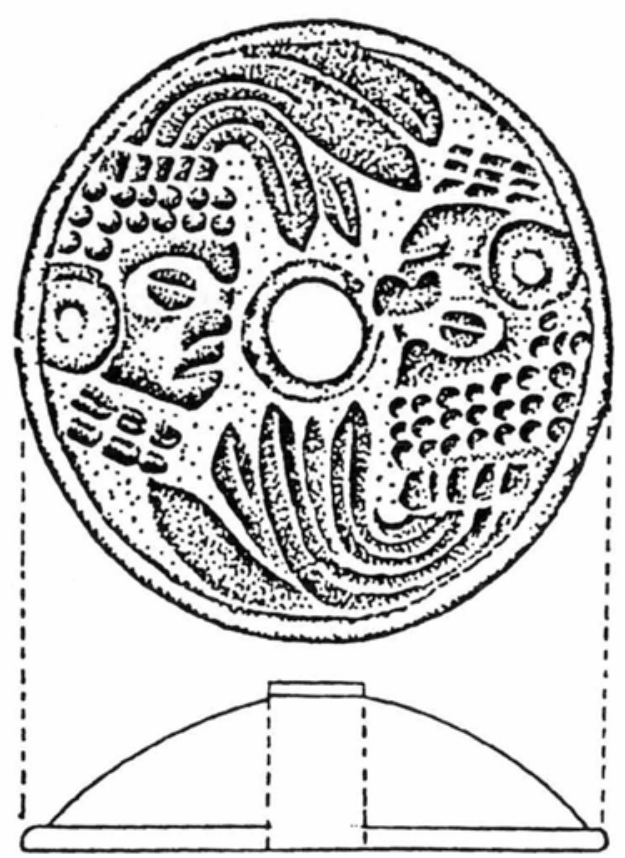

c. $3.0 \mathrm{~cm}$ diam., $8 \mathrm{~mm}$ altura, café oscuro, Culhuacan.

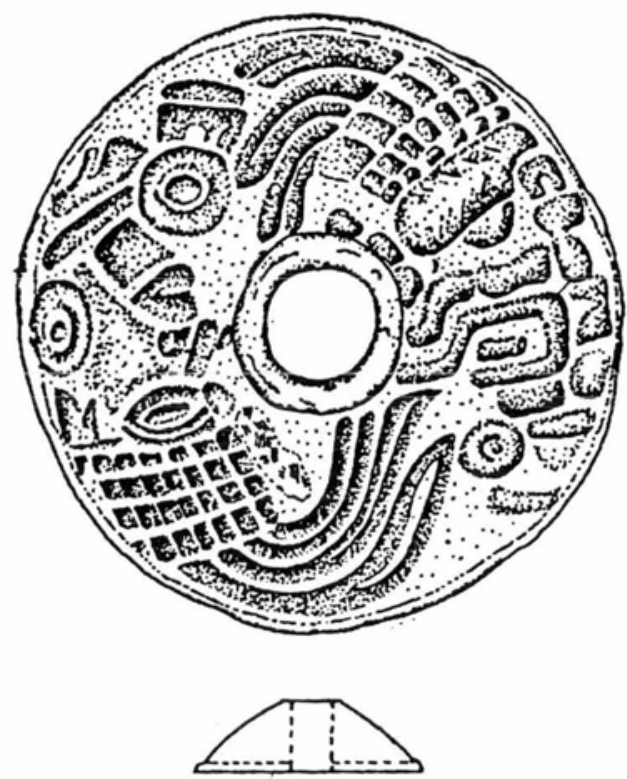

d. $3.0 \mathrm{~cm}$ diam., $1.0 \mathrm{~cm}$ altura, barro rojizo con engobe café, Culhuacan. 


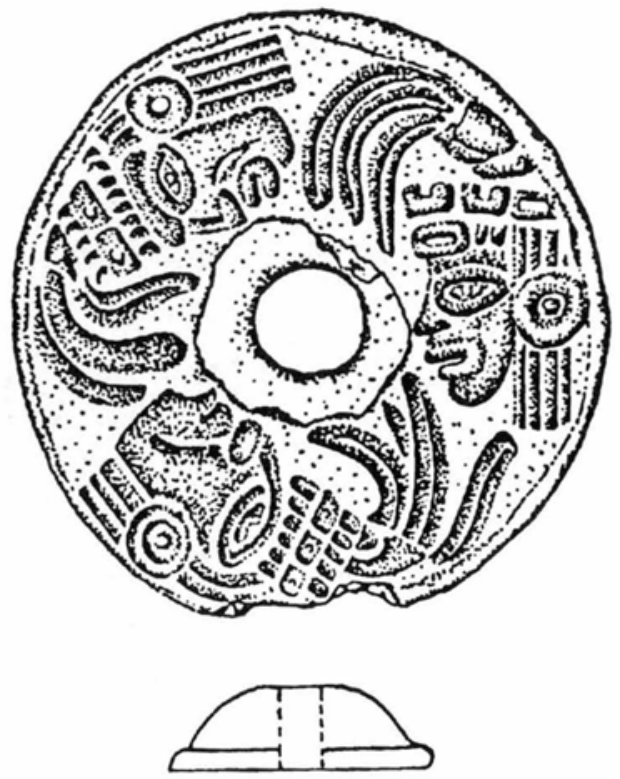

e. $3.0 \mathrm{~cm}$ diam., $9 \mathrm{~mm}$ altura, café claro, residuos de pigmento rojo, Culhuacan.

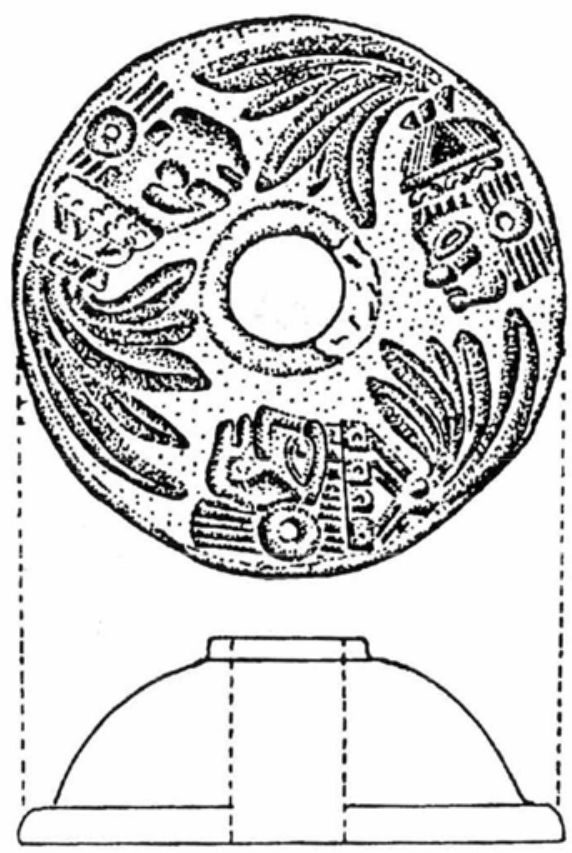

f. $3.2 \mathrm{~cm}$ diam., $1.2 \mathrm{~cm}$ altura, café claro con restos de pigmento rojo, Culhuacan 


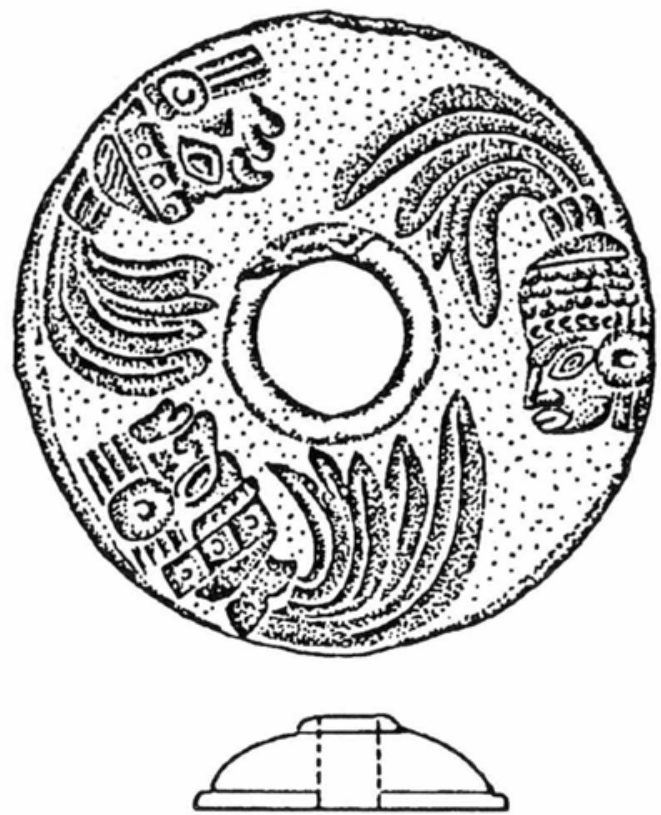

g. $3.1 \mathrm{~cm}$ diam., $1.0 \mathrm{~cm}$ altura, café claro, Culhuacan.
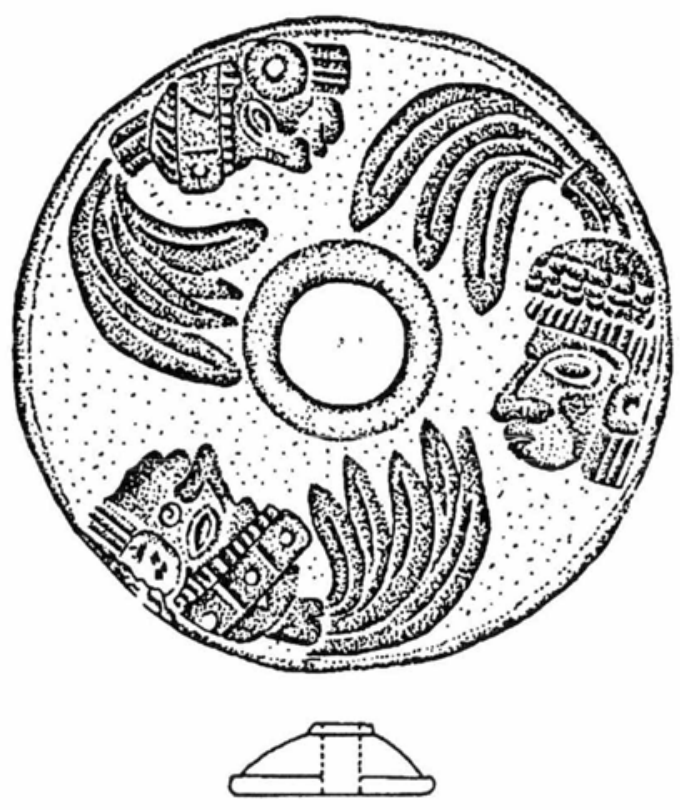

h. $2.6 \mathrm{~cm}$ diam., $9 \mathrm{~mm}$ altura, café, Culhuacan. 


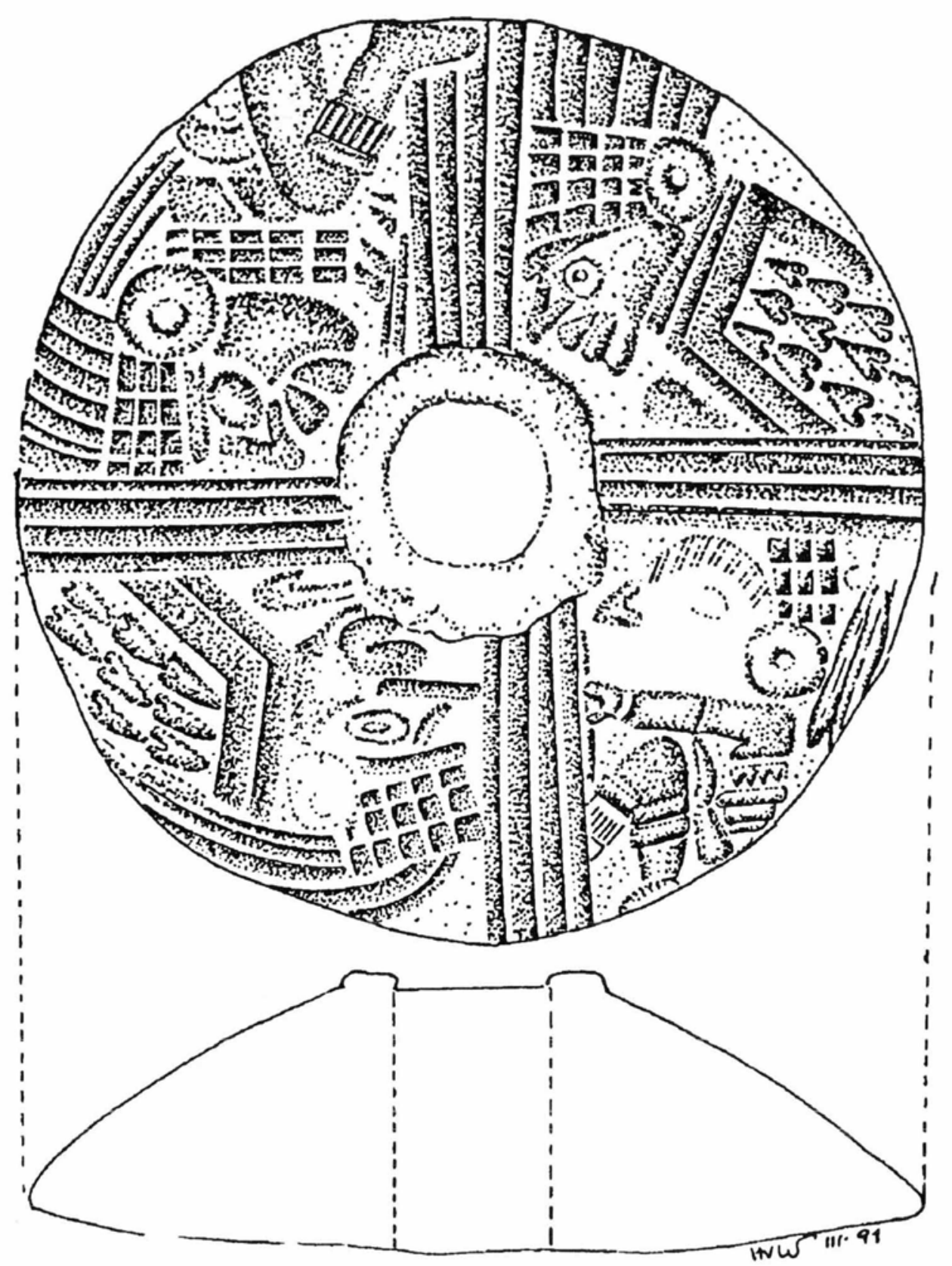

i. $4.7 \mathrm{~cm}$ diam., $1.4 \mathrm{~cm}$ altura, café claro, Valle de México 
Fig. 4 Malacates con 2 rostros similares alternando con otros diseños

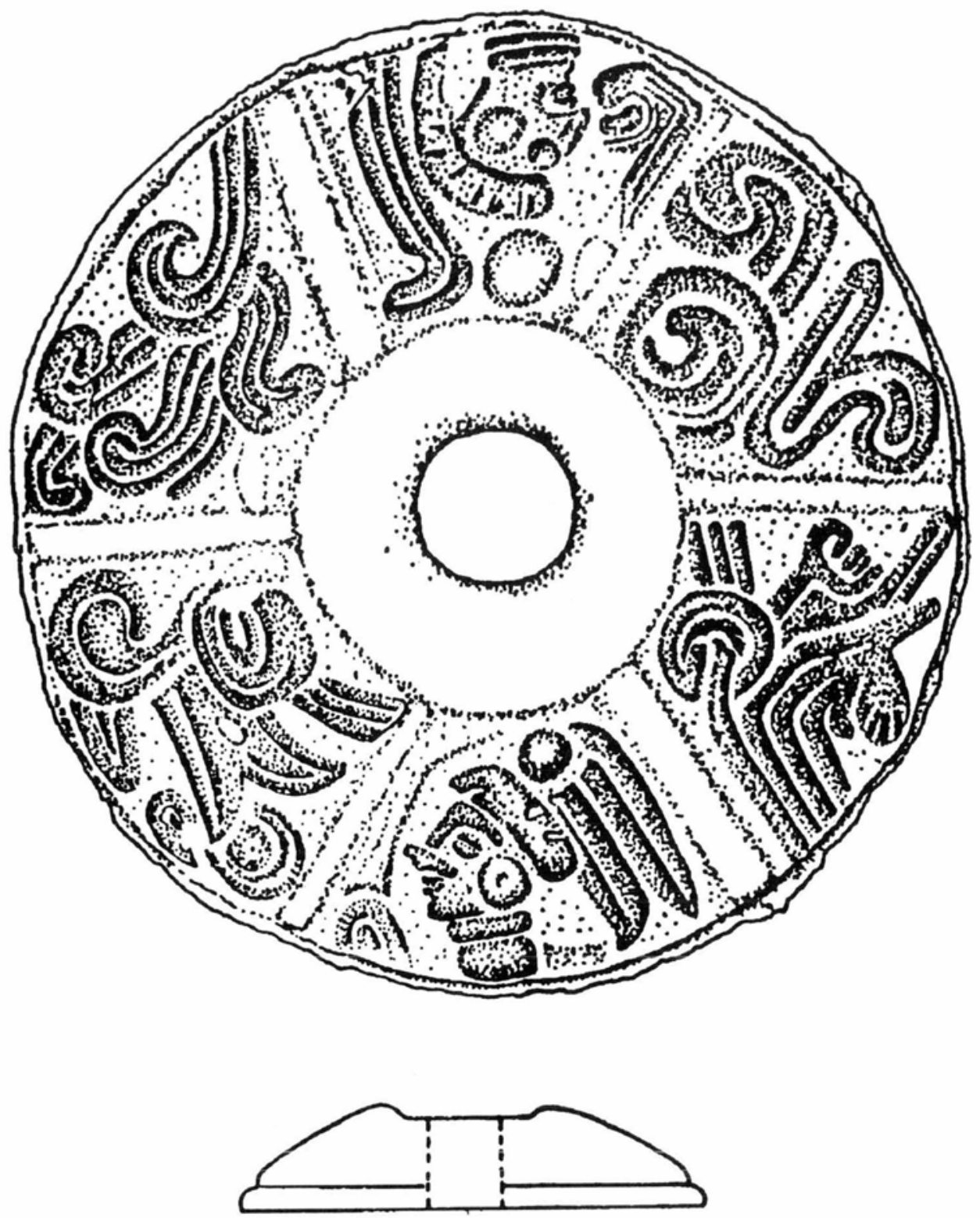

a. $5.0 \mathrm{~cm}$ diam., $1.1 \mathrm{~cm}$ altura, café claro pulido, Ahuixotla. 


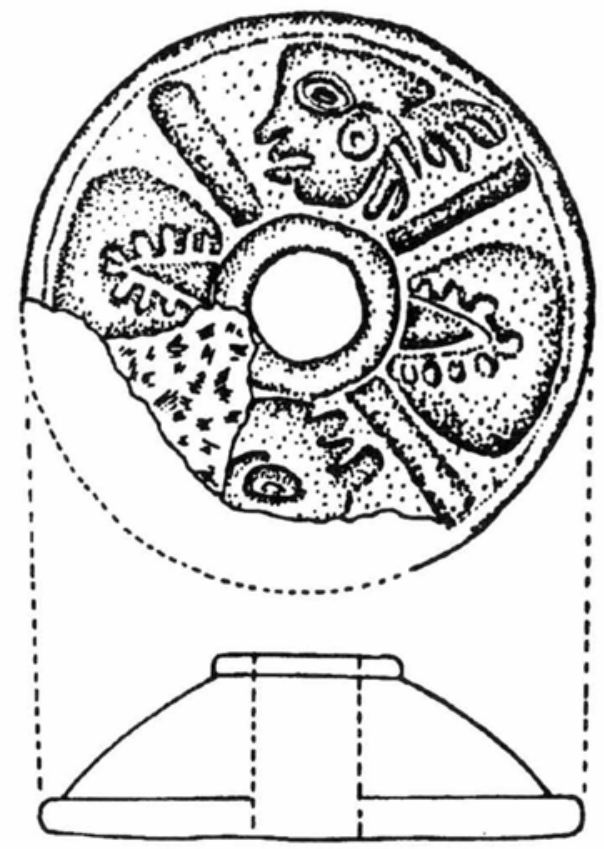

b. $4.9 \mathrm{~cm}$ diam., $1.8 \mathrm{~cm}$. altura, café claro pulido, Xico.

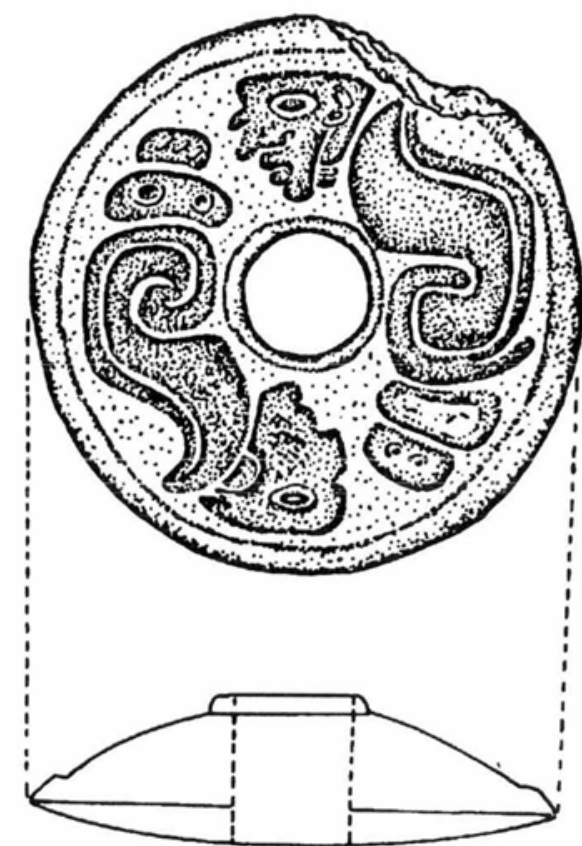

c. $5.0 \mathrm{~cm}$ diam., $1.6 \mathrm{~cm}$. altura, café, Culhuacan. 


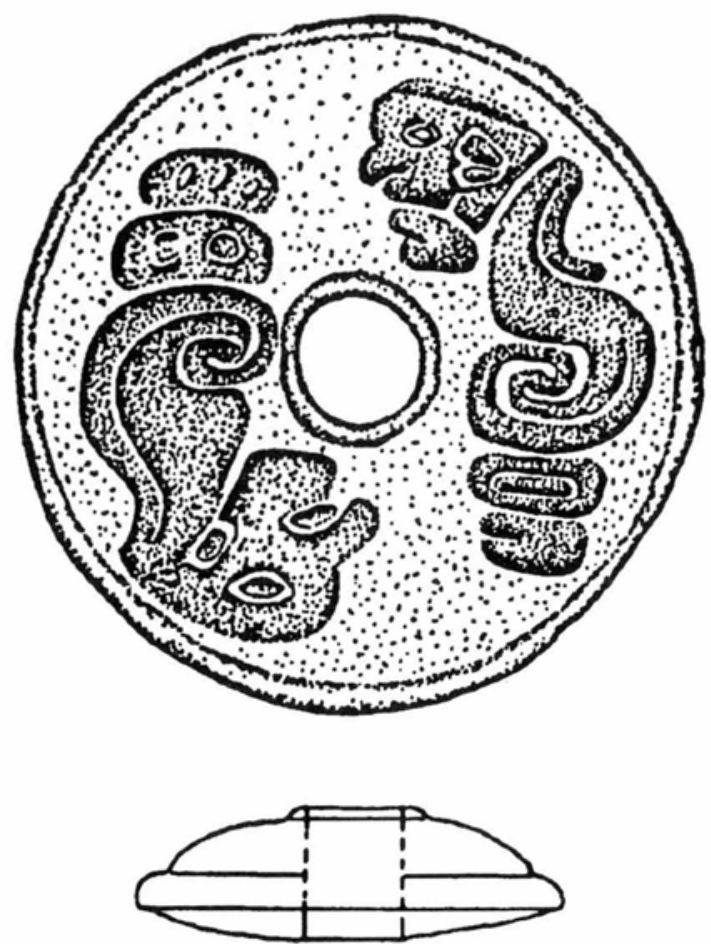

d. $4.5 \mathrm{~cm}$ diam., $1.3 \mathrm{~cm}$ altura, gris, Culhuacan.

Fig. 5 Malacates con figuras humanas de cuerpo entero
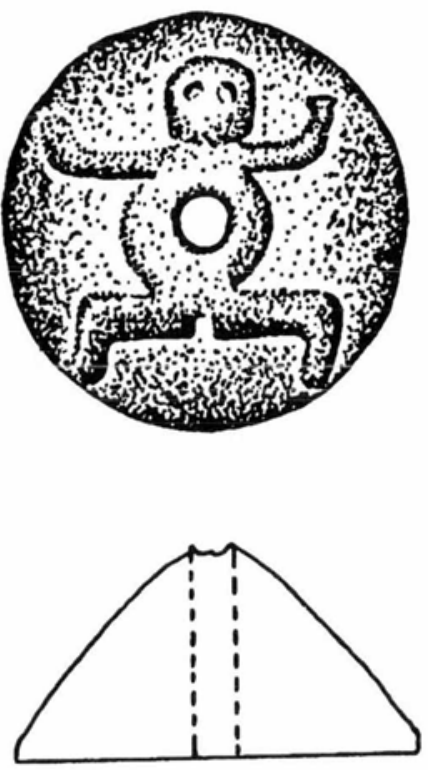

a. $2.0 \mathrm{~cm}$ diam., $1.1 \mathrm{~cm}$ altura, café, Culhuacan. 

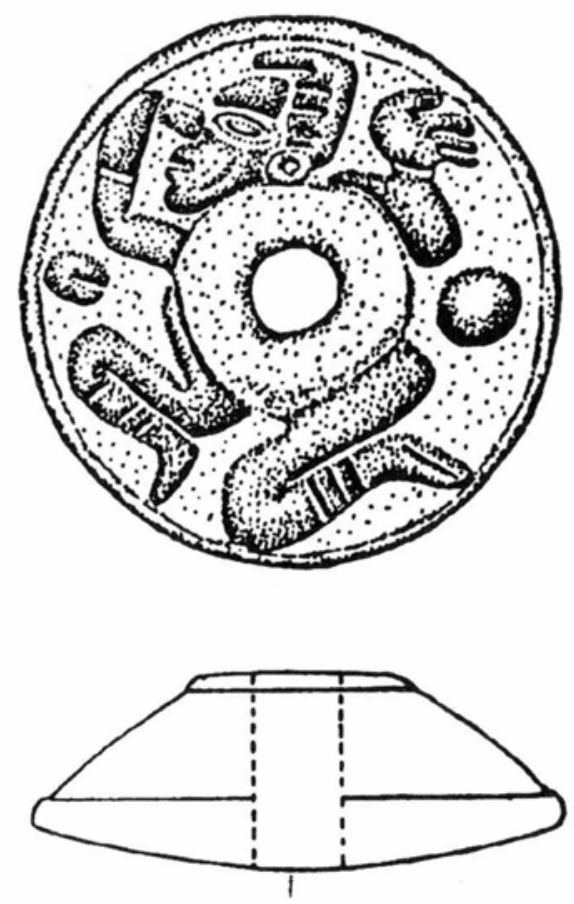

b. $2.8 \mathrm{~cm}$ diam., $1.0 \mathrm{~cm}$ altura, café claro, Texcoco.

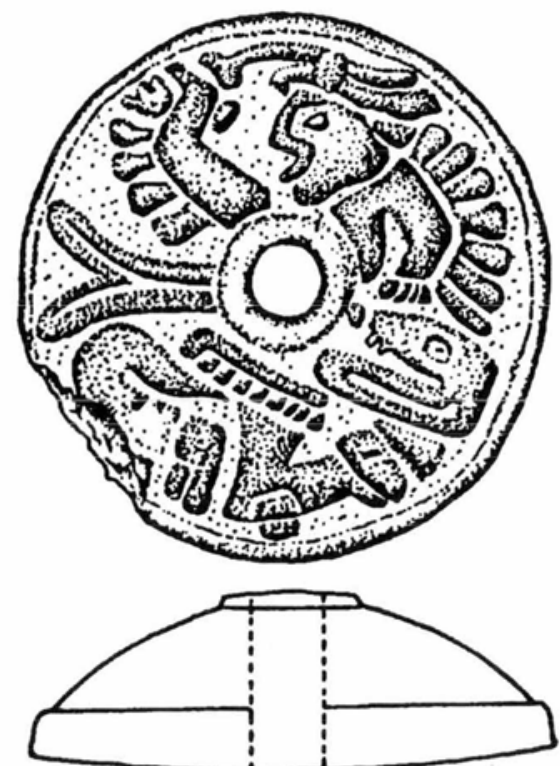

c. $3.0 \mathrm{~cm}$ diam., $9 \mathrm{~mm}$ altura, engobe rojizo, Culhuacan. 


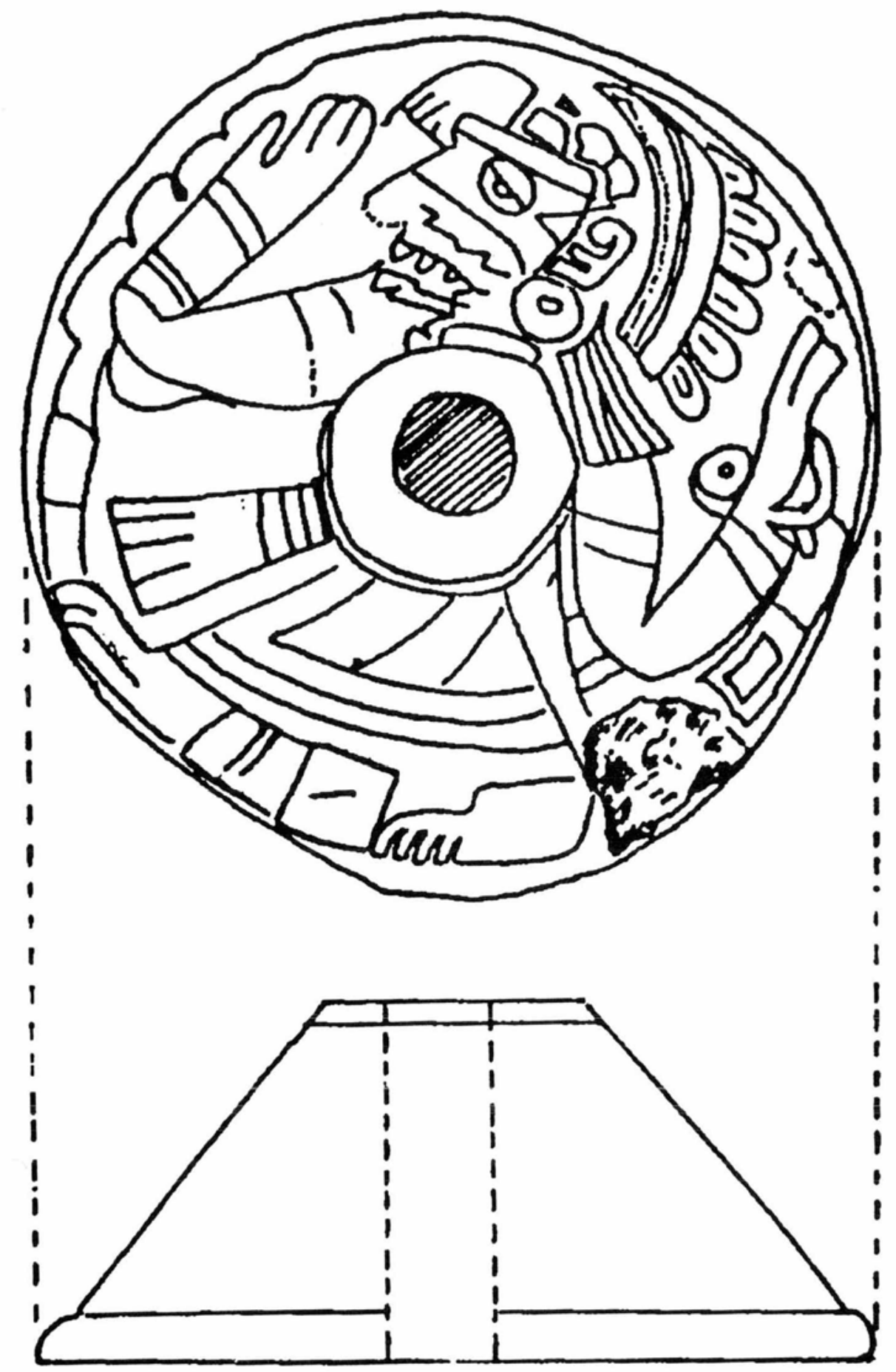

d. $5.4 \mathrm{~cm}$ diam., $2.5 \mathrm{~cm}$ altura, café, inciso, Santa Lucía, Azcapotzalco. 


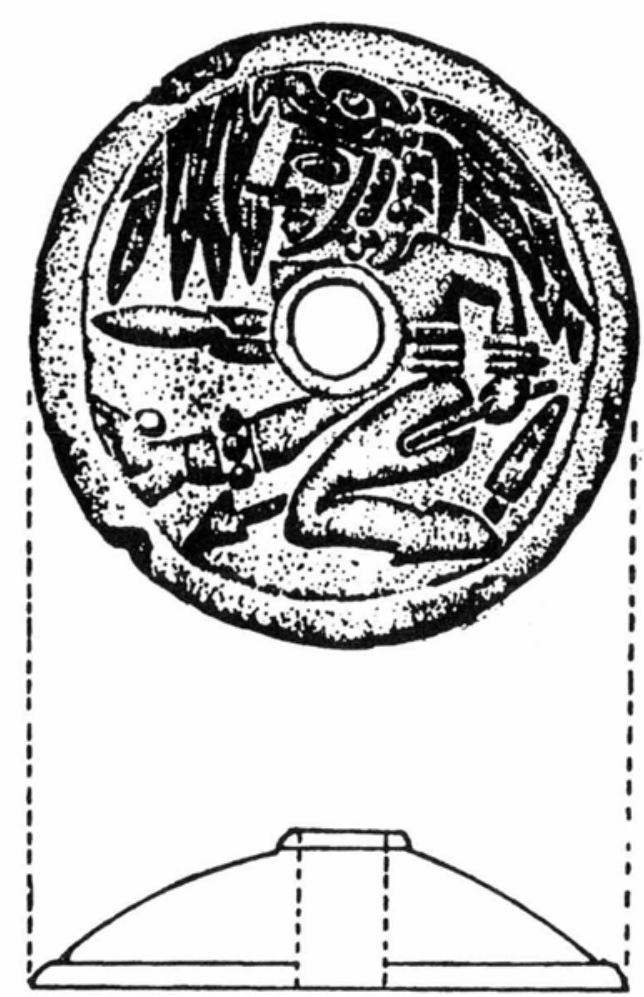

e. $5.4 \mathrm{~cm}$ diam., $1.3 \mathrm{~cm}$ altura, café claro, Culhuacan.
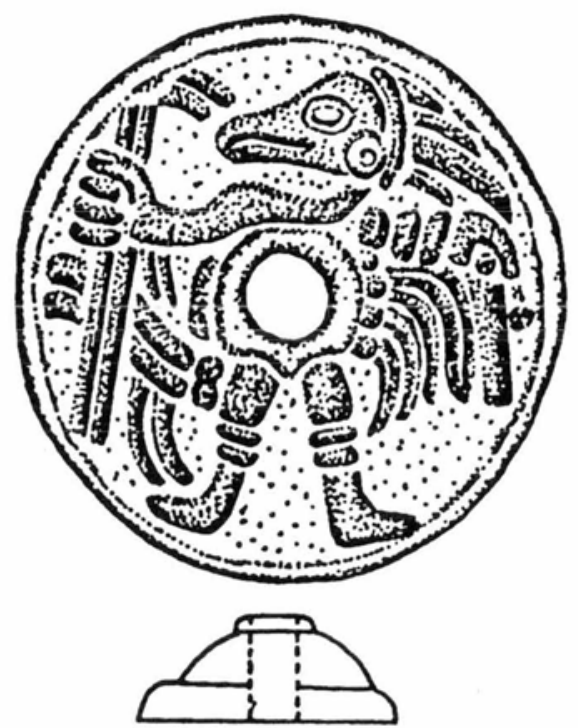

f. $2.8 \mathrm{~cm}$ diam., 1.0 altura, café oscuro, restos de pintura negra en la parte plana, Culhuacan. 


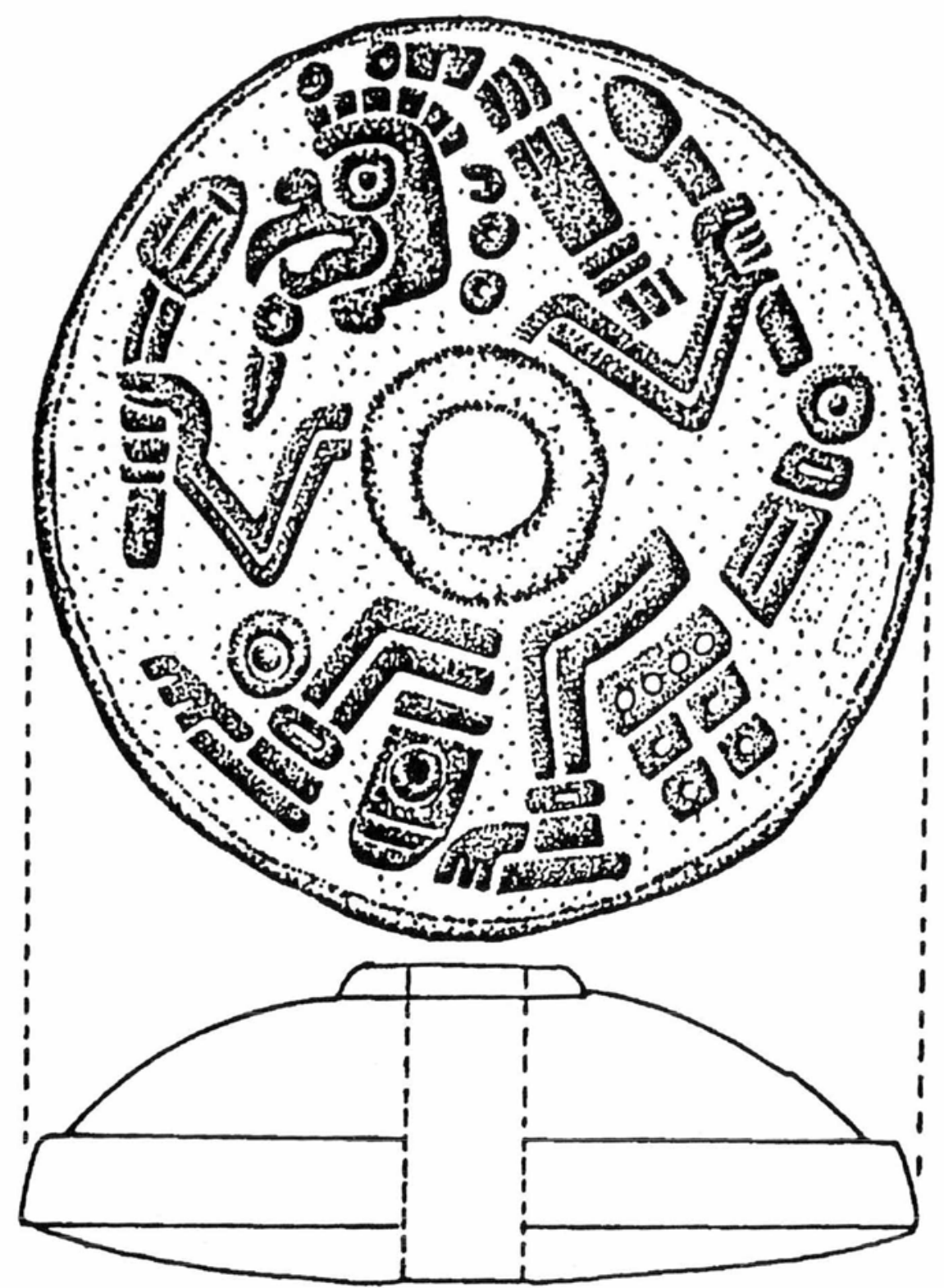

g. $2.3 \mathrm{~cm}$ diam., $1 \mathrm{~cm}$ altura, café pulido. Procede de Teotihuacan según reporte. Colección particular, Nuevo México, E.U. 

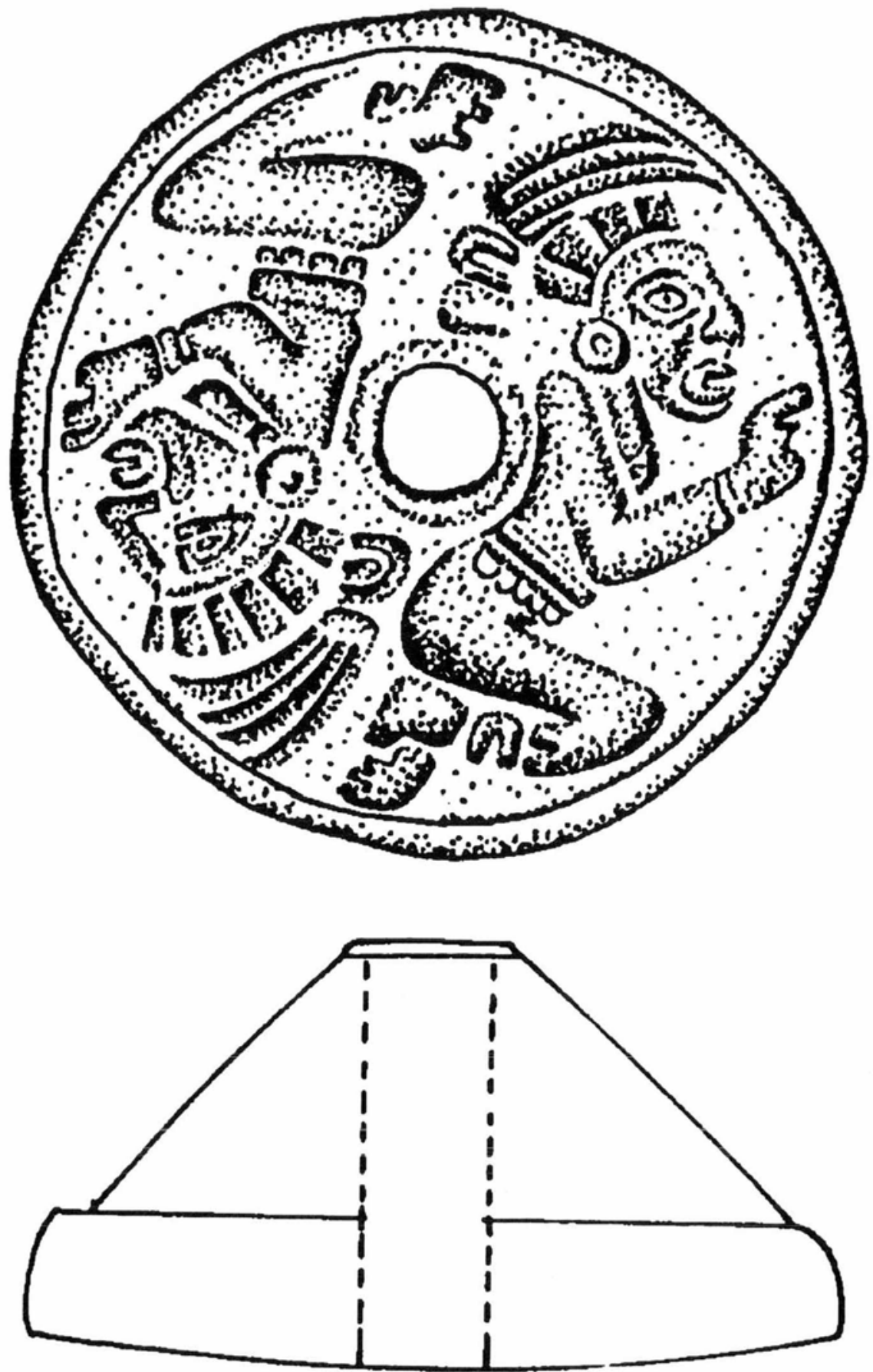

Fig. 5 h. $2.3 \mathrm{~cm}$ diam., $1.2 \mathrm{~cm}$ altura, café oscuro, pulido, con residuos de pigmento verde-azul, Huexotla. 


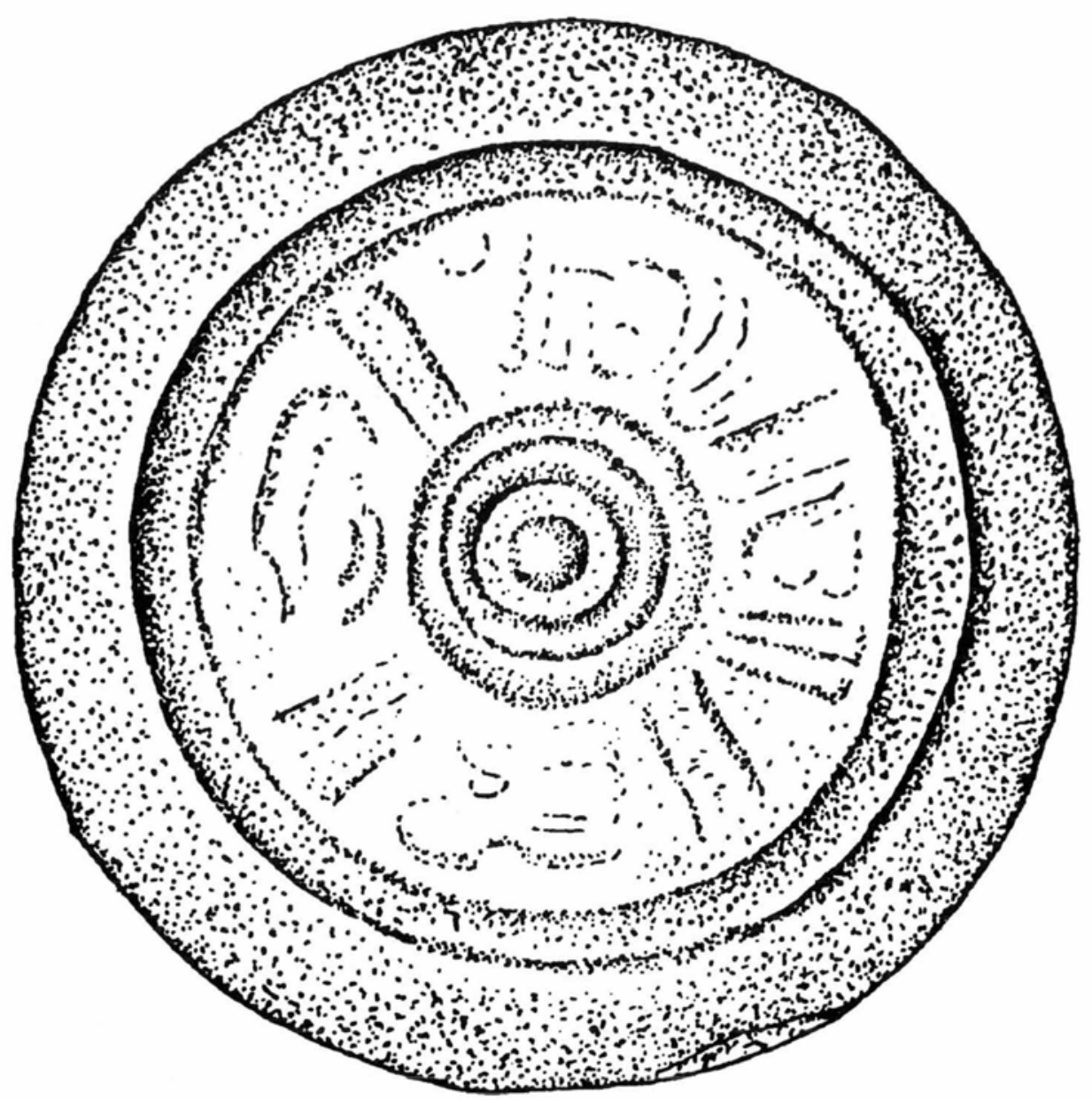

Fig. 6a Molde, $5.2 \mathrm{~cm}$ diam., $2.4 \mathrm{~cm}$ altura, café rojizo, Chalco. 
6b Impresión reciente.

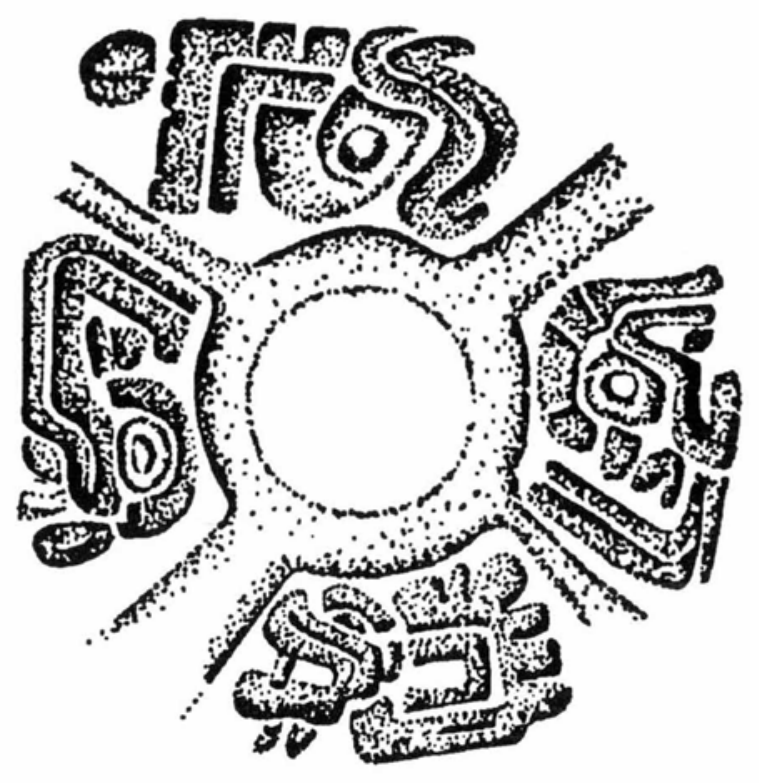

Fig. 7 Comparación de los malacates figuras $2 a$ y $2 b$ con esculturas toltecas de Tula

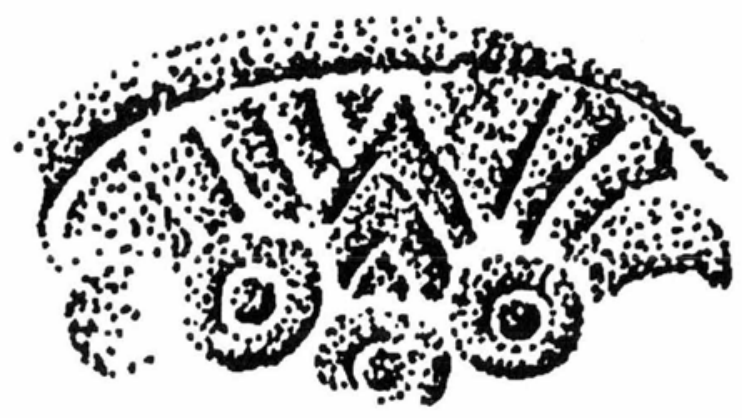

7a Estela II, Tula, según Catálogo Tula, Fig. 99.

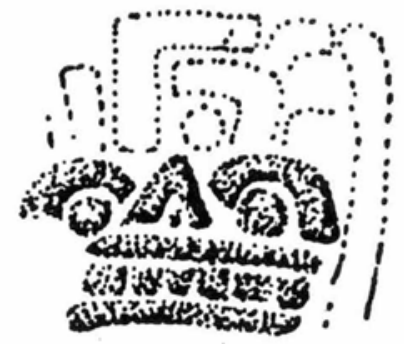

7b Estela III, según Catálogo Tula, Fig. 100. 
DOI: http://dx.doi.org/10.22201/iie.18703062e.1993.64.1665

Fig. 8 Diseños esquematizados de malacates en las obras de Horcasitas et al. (1961) y Enciso (1971) comparados con figuras en este trabajo

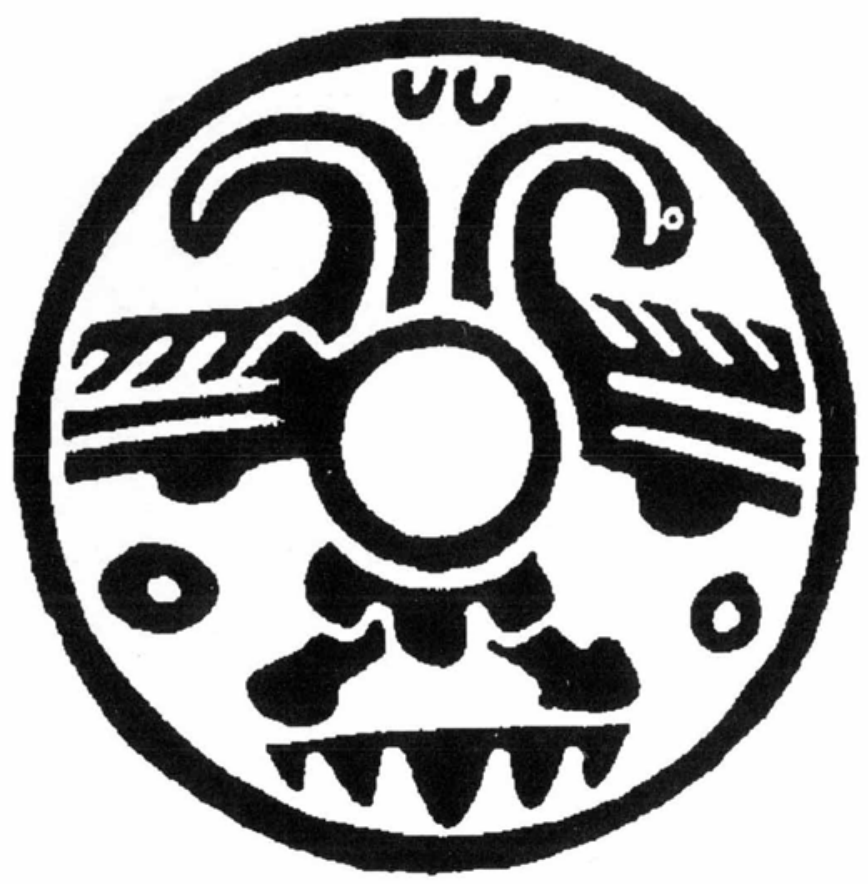

8a Enciso 48a -Fig. 2d

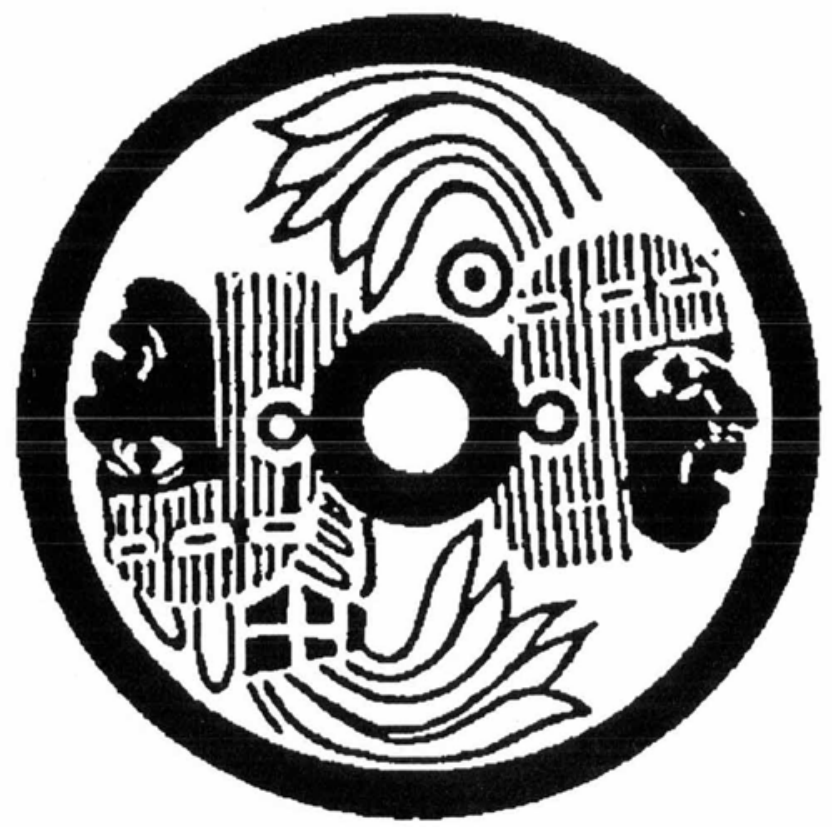

b Horcasitas I:2

(Tenayuca) -Fig. 3b 


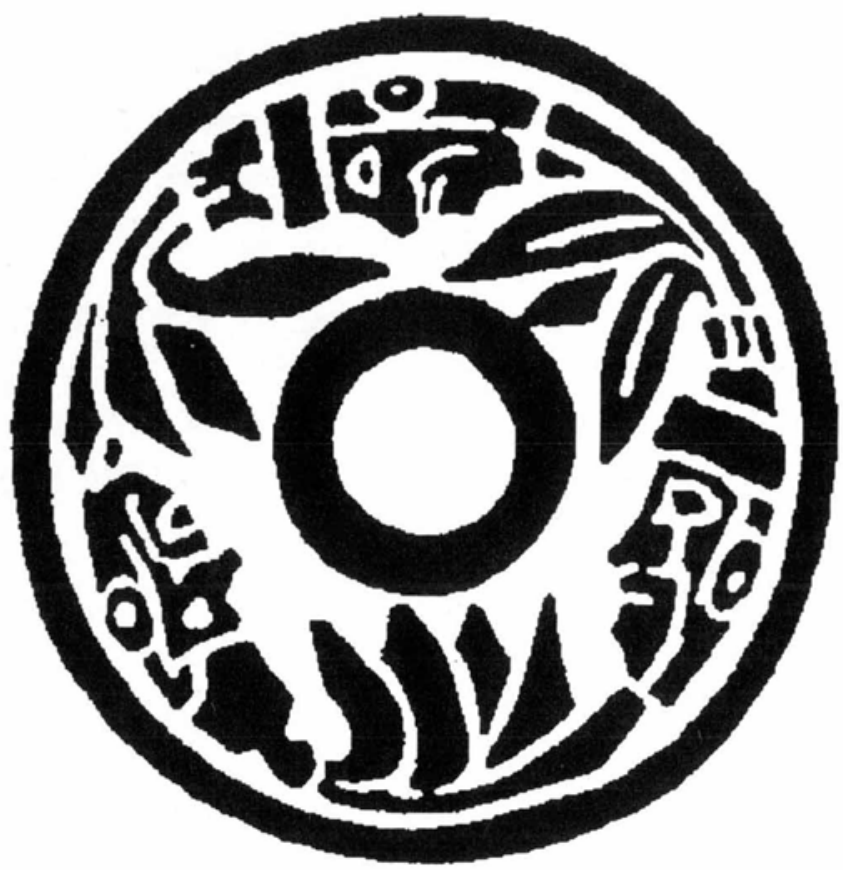

c Enciso 49d - Fig. 3e

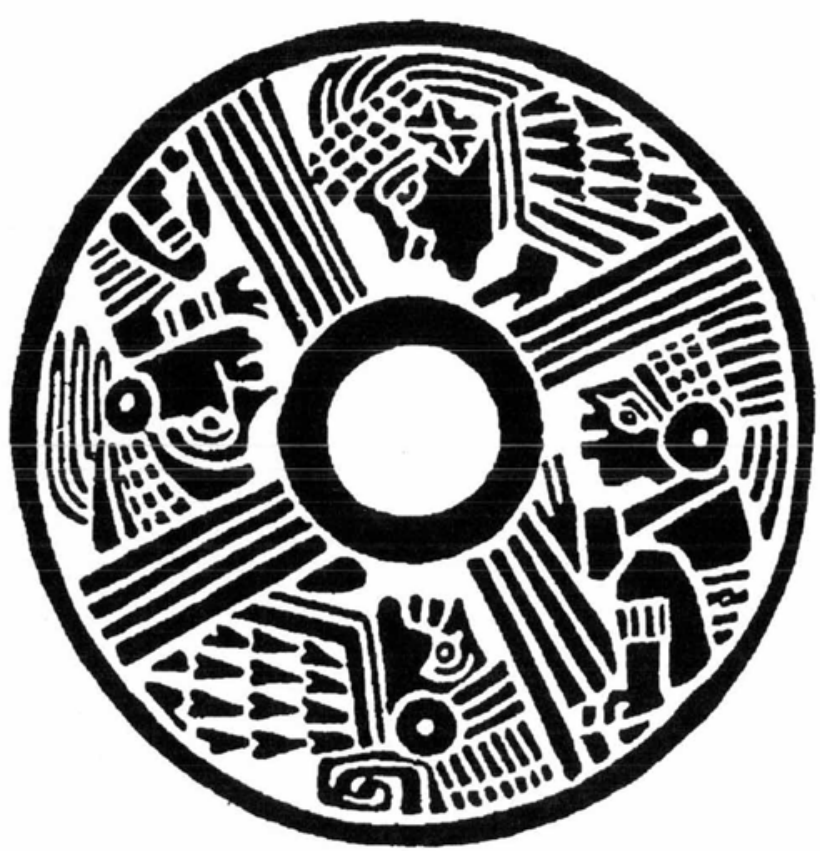

d Enciso 28a -Fig. 3i 


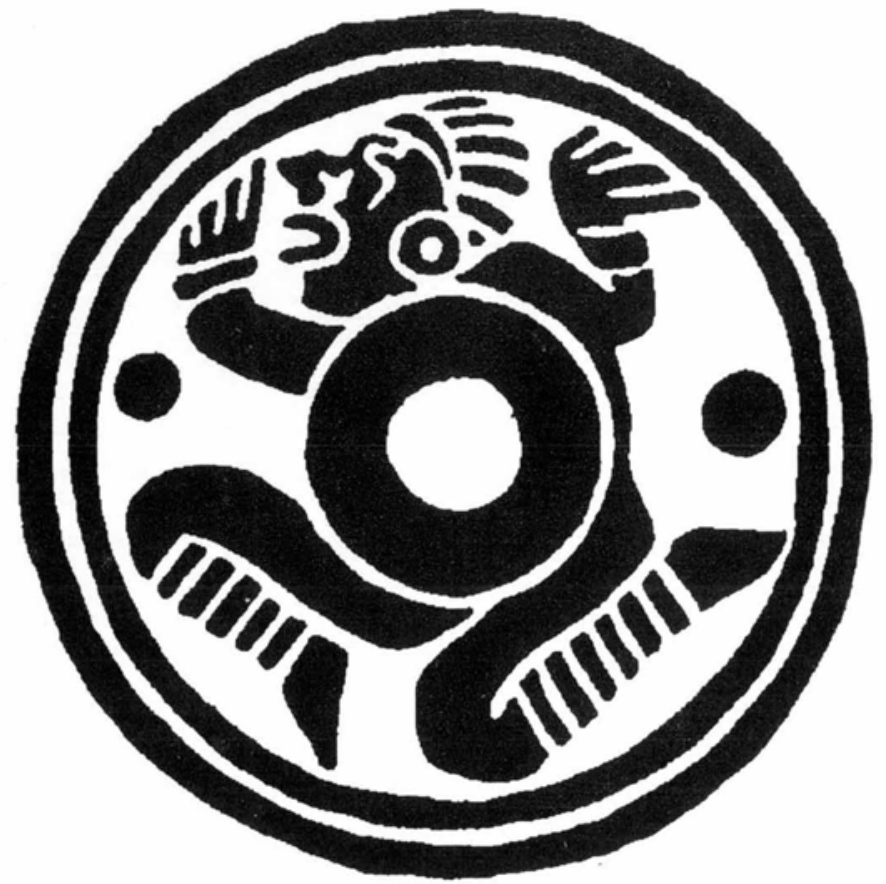

e Enciso 50c -Fig. 5b

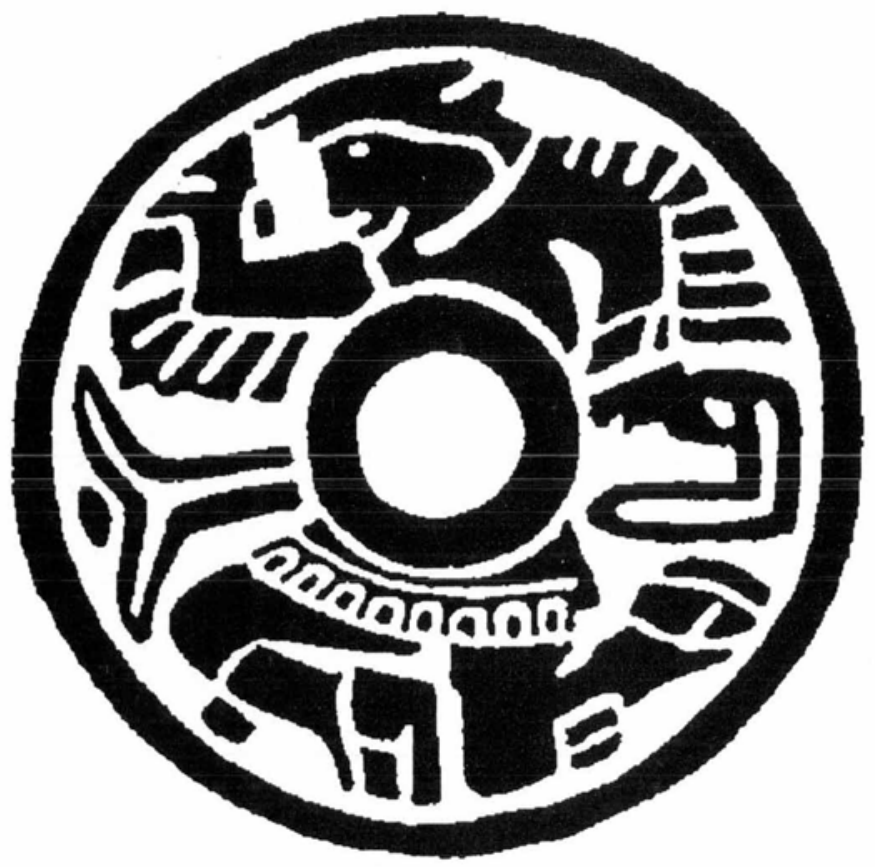

f Enciso $50 \mathrm{~b}-$ Fig. $5 \mathrm{c}$ 


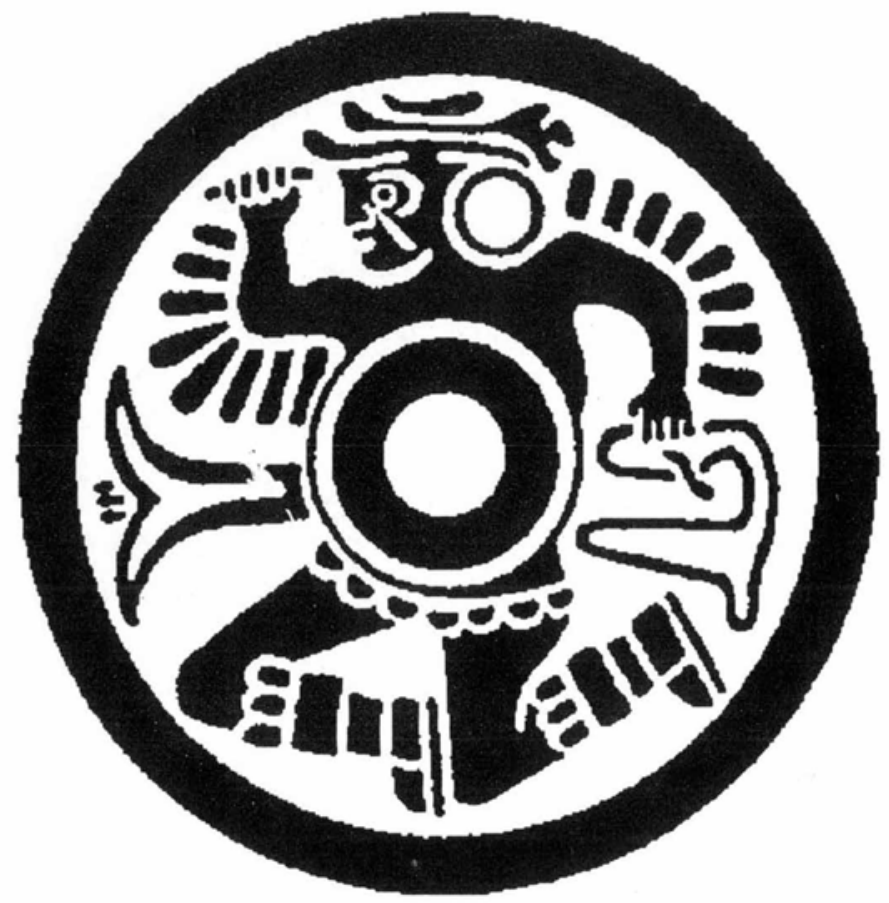

g Horcasitas I: 1

(Tezcoco) -Fig. 5c

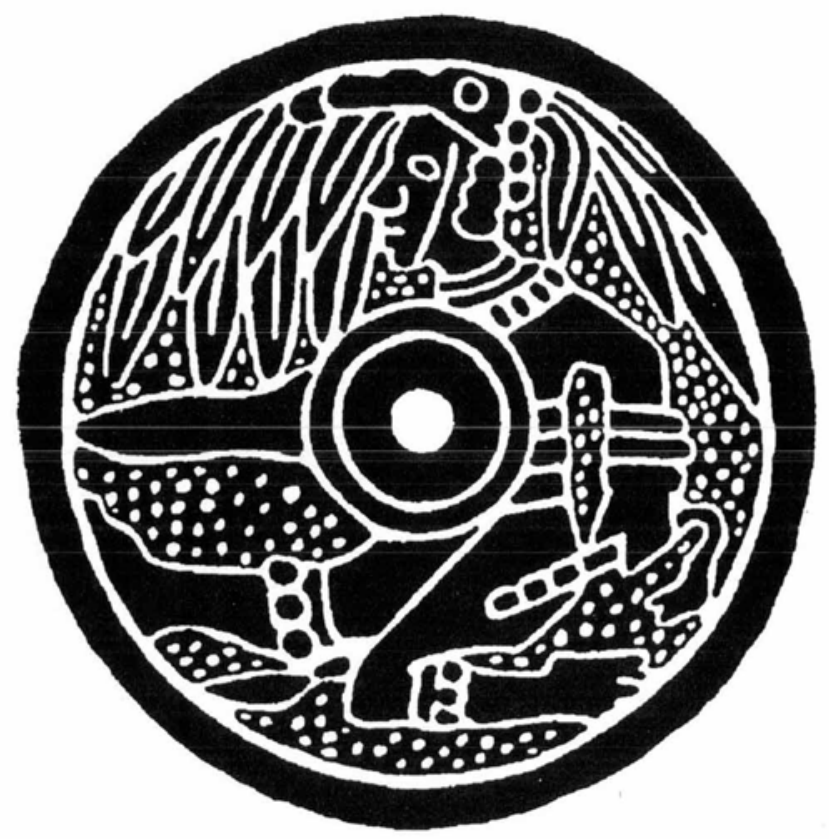

h Enciso 28c -Fig. 5e 


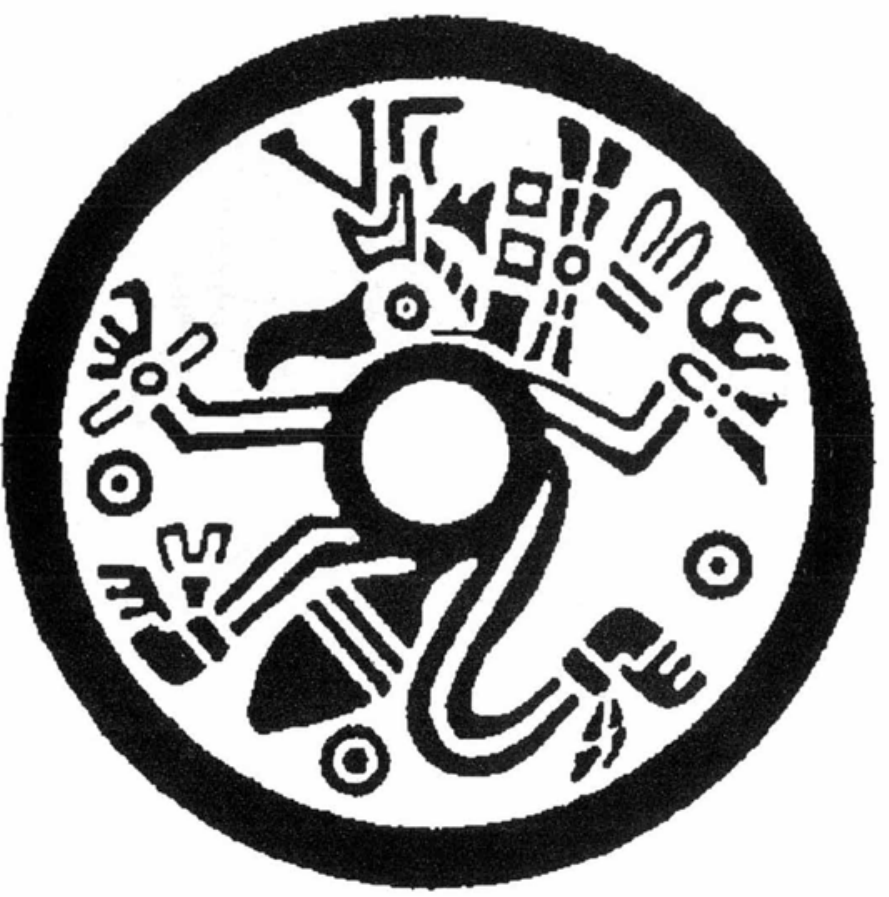

i Horcasitas I:7

(Tezcoco) -Fig. 5g

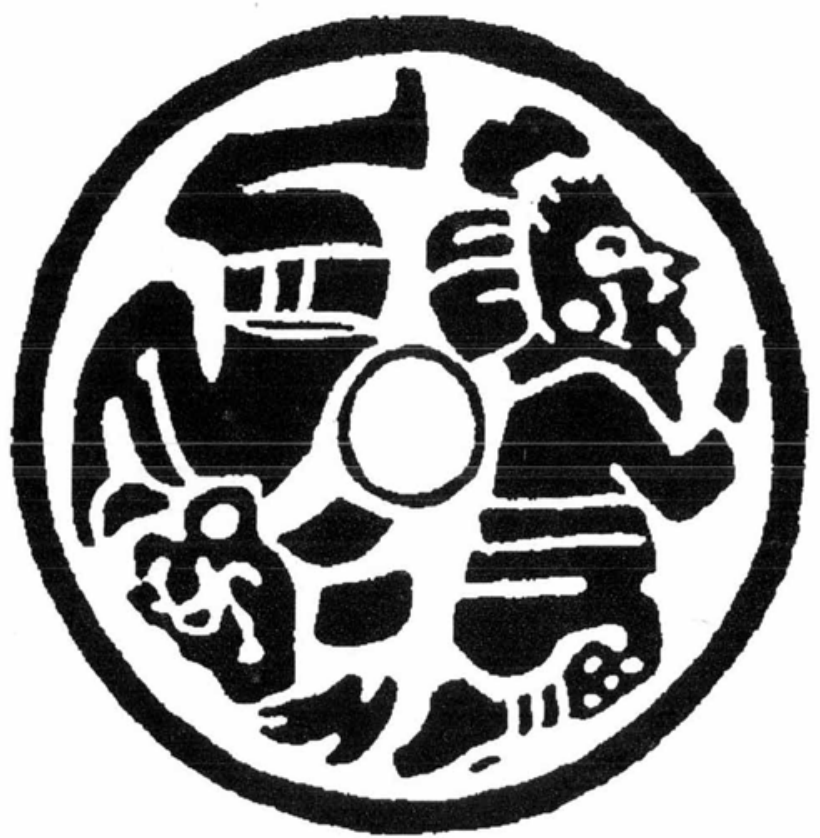

j Enciso 28b -Fig. 5h 
Fig. 9 Indumentaria tolteca - penachos

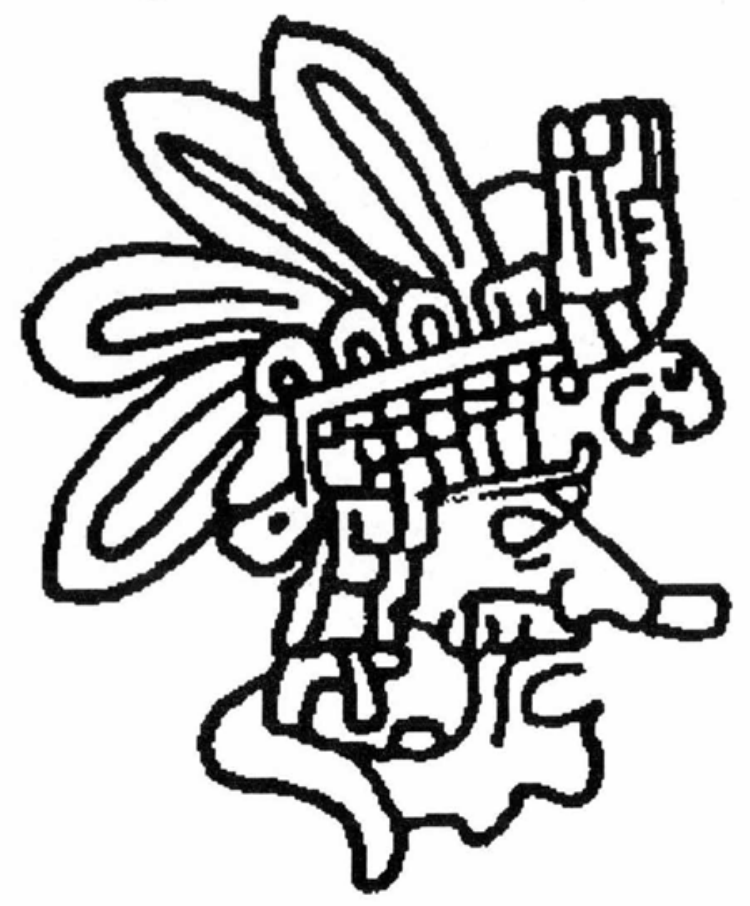

9a Guerrero tolteca, Pilar III, según Acosta 1941, Fig. C.

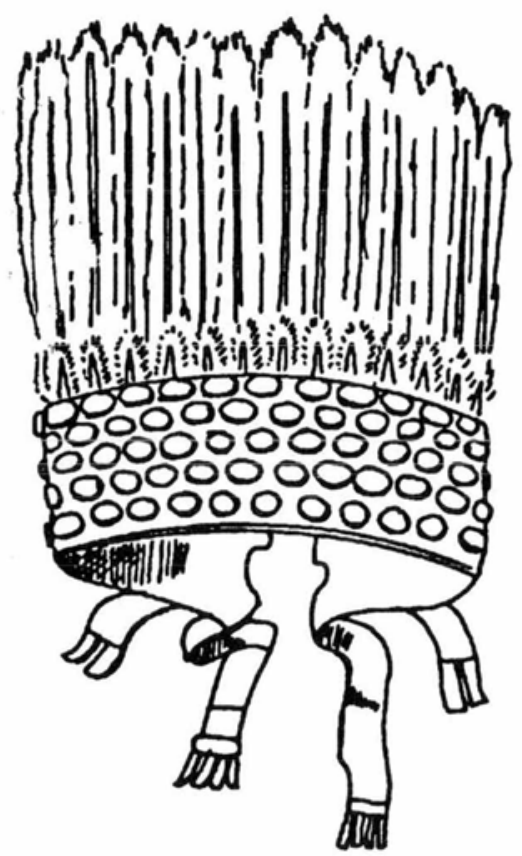

9b Penacho de los atlantes monumentales de Tula, según Acosta 1961, Fig. 2. 


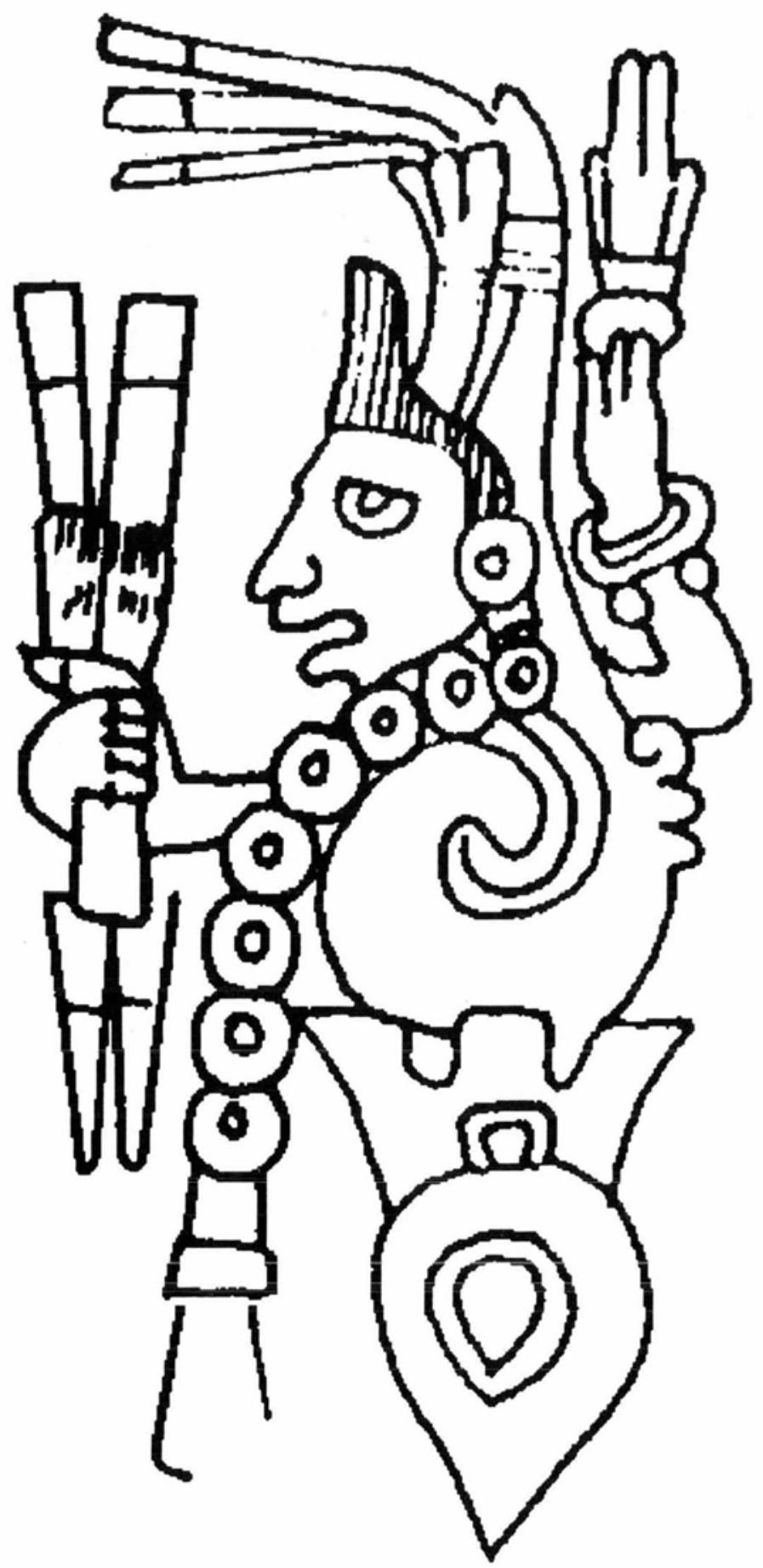

Fig. 10 Tecciztli, nacimiento del dios de la guerra, Códice Borgia 8. 


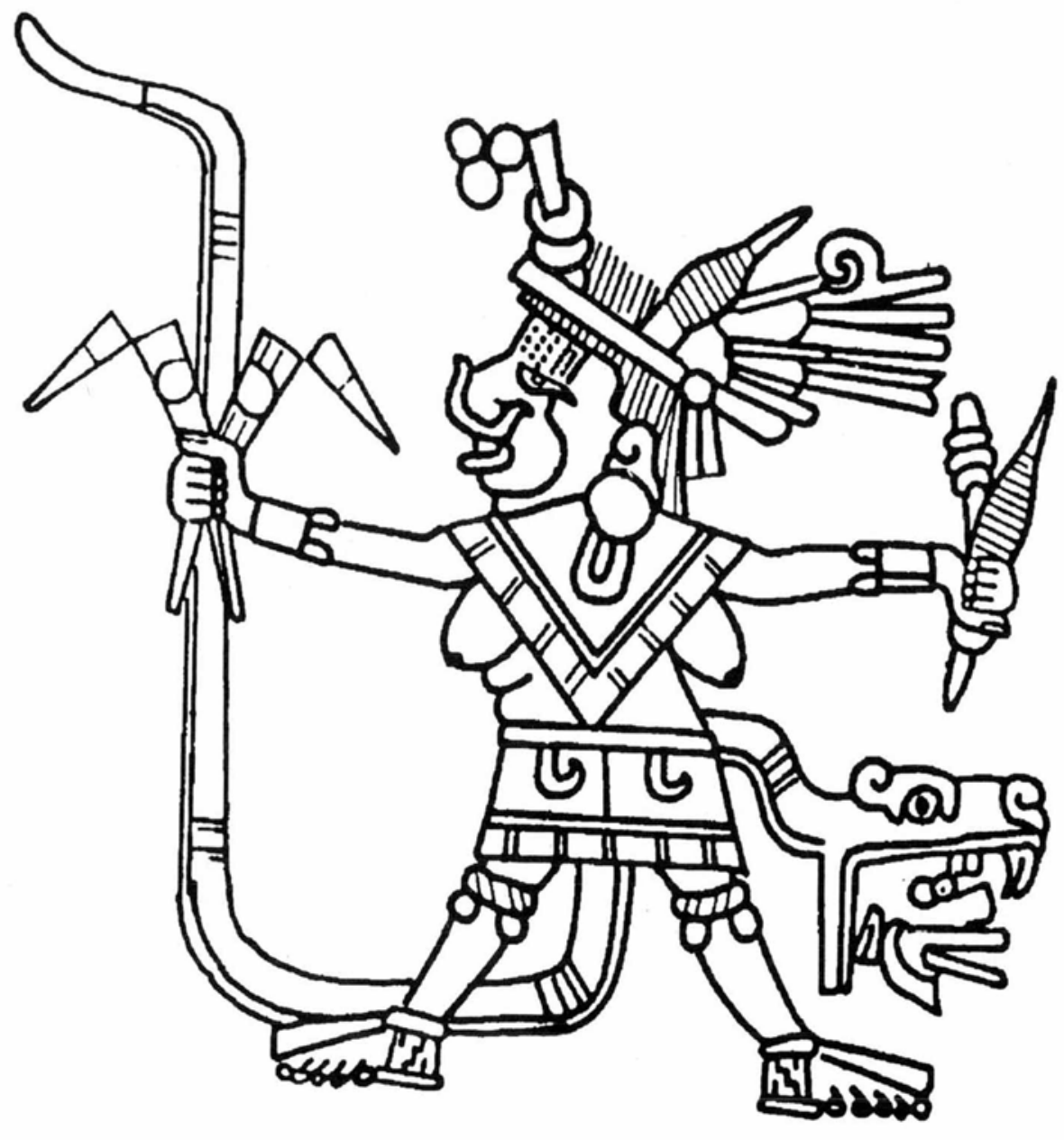

Fig. 11 Tlazolteotl, diosa lunar, con huso en el tocado y otro en la mano. Códice Land 32. 


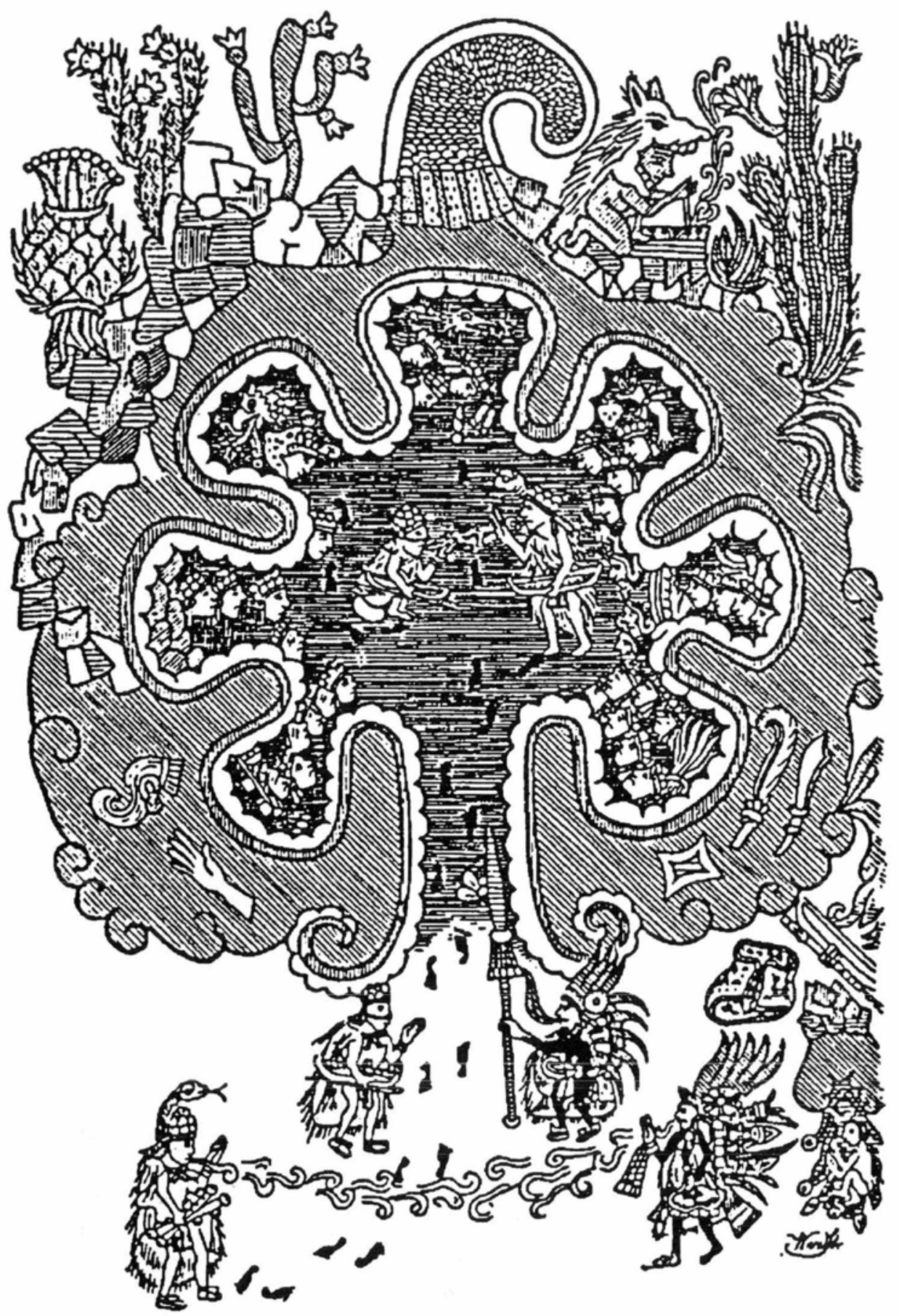

Fig. 12 La cueva de Chicomoztoc, según La historia tolleca-chichimeca. 


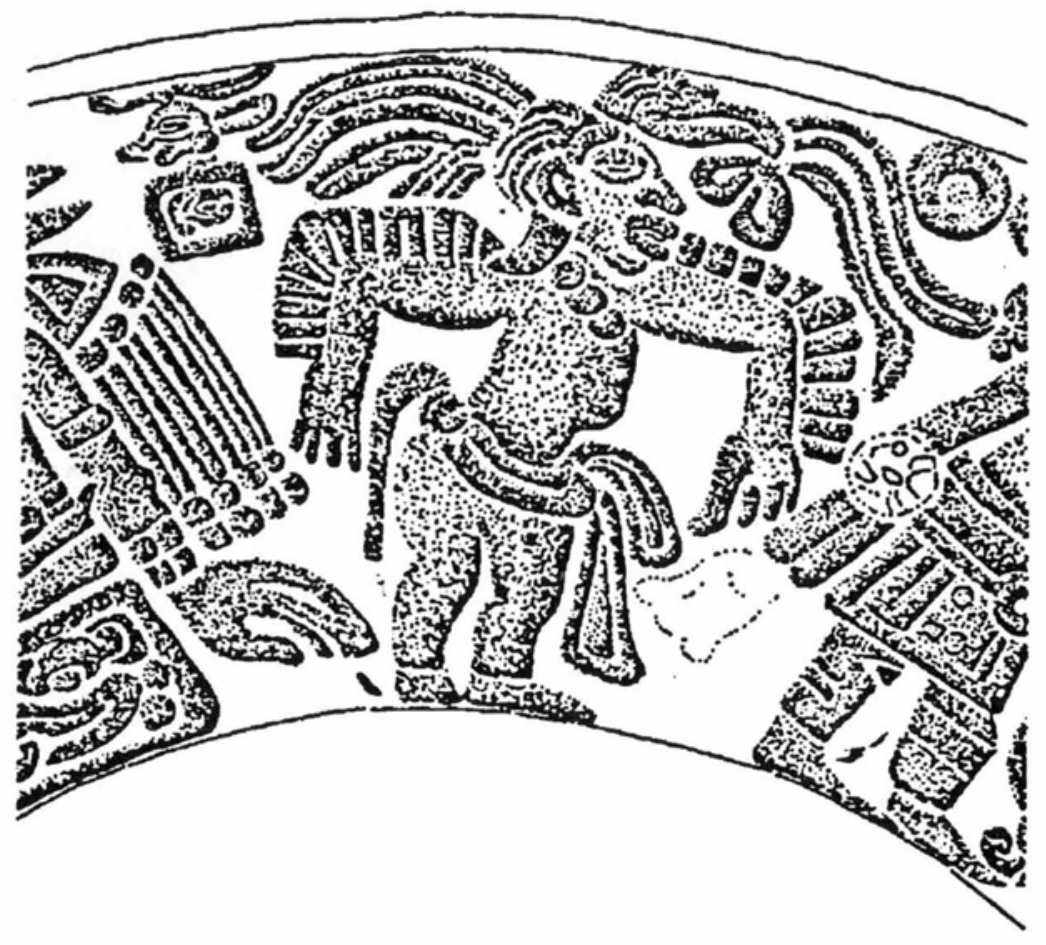

Fig. 13 Individuos “alados” en la cerámica de Río Blanco, Veracruz, según von Winning 1971:Fig. 1(a) y 2(b).
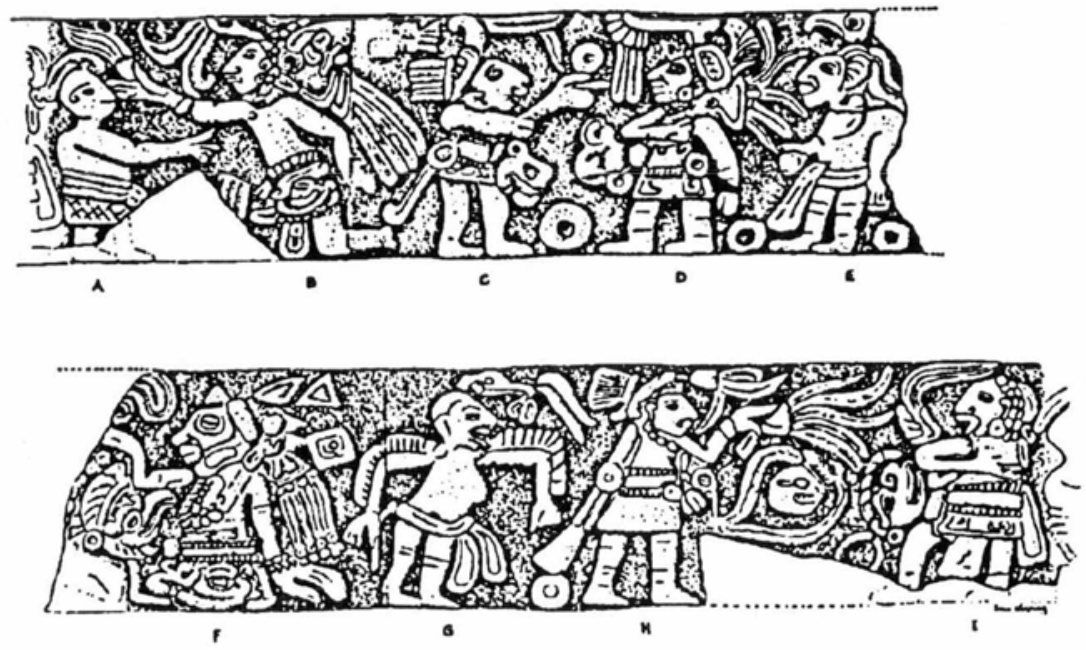


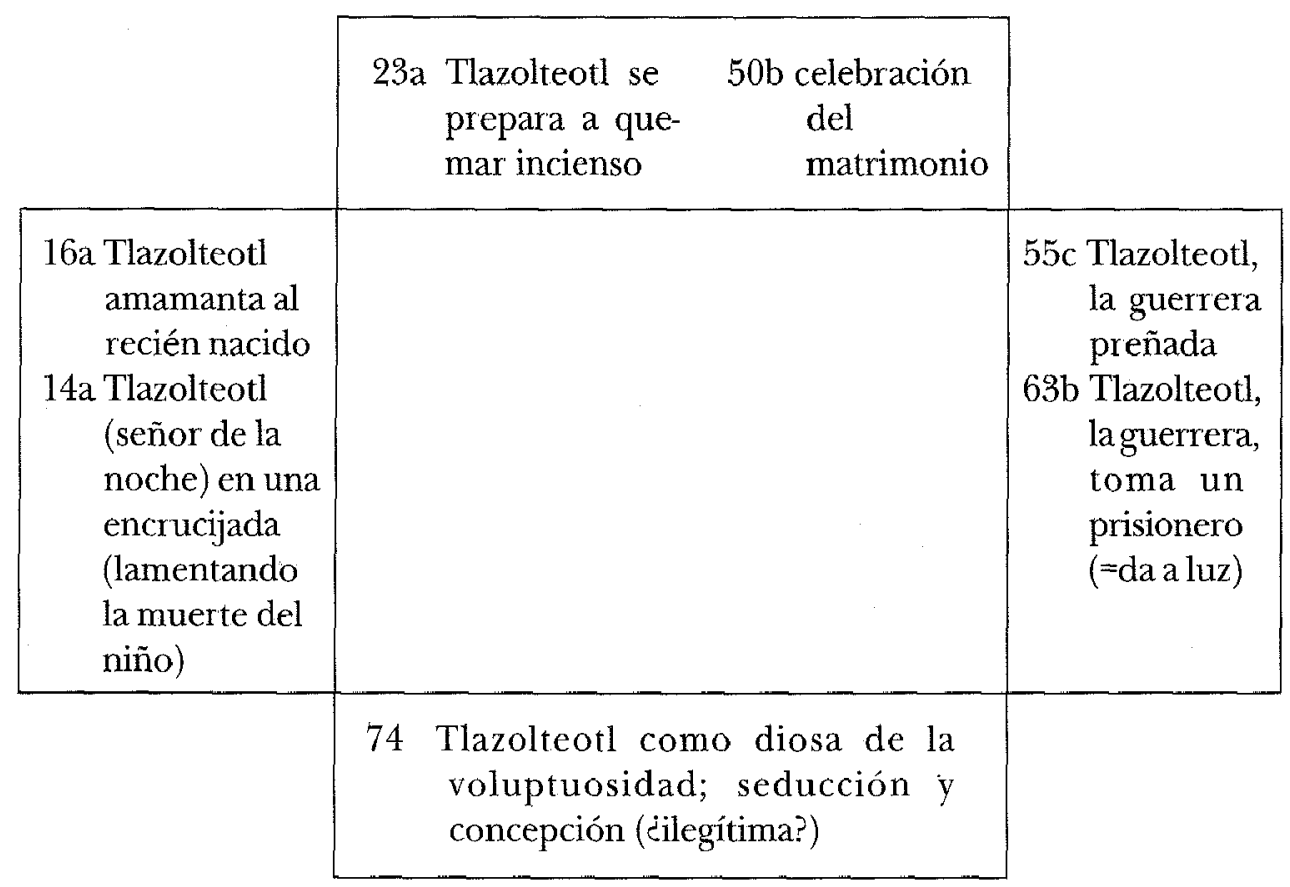

En resumen, un malacate metafóricamente causa el embarazo mediante su movimiento durante el acto de hilar y contribuye al ensanchamiento del cuerpo de la madre hasta el parto y hasta dar de mamar.

Finalmente citamos un episodio histórico que señala cómo se consideraba al malacate una insignia femenina en contraste con los penachos de los guerreros masculinos. Bajo el régimen de Itzcoatl los mexica persiguieron a los tepanecas hasta Coyoacan (1428-1429). "Llegando al ar eito y mitote en la plaza y templo vieron a los tepanecas que en lugar de plumaje traían husos de mujer, malacates nombrados, a los cuales comenzó luego a traer presos a los principales de los tepanecas" (Tezozomoc 1944:55).

\section{Resumen}

Los malacates de la Cuenca de México, cuya decoración en relieve representa figuras humanas, se distinguen por su simbolismo relacionado con el arte escultórico tolteca. La temática y la finura del grabado, así como el buen estado de conservación de esta colección de 28 ejemplares, sugieren que se trata de malacates destinados para el uso ritual y conmemorativo. Dichos 
malacates fueron hallados por campesinos de las antiguas poblaciones de Culhuacan, Huexotla y Xico (estas dos últimas dependían de Texcoco), o sea en la región al sur y sureste de Tenochtitlan.

Durante el Posclásico estos señoríos fueron gobernados simultáneamente por dos o tres y hasta por cuatro jefes. Por lo tanto, aquellos malacates con dos o tres cabezas con diferentes rostros individualizados, que asemejan verdaderos retratos, conmemoran posiblemente personajes históricos de filiación ancestral tolteca. Además se observan variedades en los ornamentos personales que distinguen a los diferentes corregidores.

Los demás temas esculpidos incluyen personajes, deidades y escenas mitológicas conocidas en la iconografía del centro de México.

Además de investigar la iconografía de los diseños que tratan de temas sociopolíticos, se analiza la función ritual-religiosa de los malacates en general Aparte del uso utilitario por las hilanderas, los malacates (husos) manifiestan un simbolismo relacionado con la maternidad, la diosa Tlazolteotl, y el calendario lunar que determina el tiempo de la preñez según los códices Laud y Borgia.

\section{BIBLIOGRAFÍA}

Acosta, Jorge R.

1941 "Los últimos descubrimientos arqueológicos en Tula, Hgo", Revista Mexicana de Estudios Antropológicos, 5:2-3, pp. 239-248.

1961 "La indumentaria de las cariátides de Tula", Homenaje a Pablo Martínez del Rìo, México, pp. 221-228.

Barthel, Thomas S.

1972 Asiatische Systeme im Codex Laux. Tribus, Veröffentlichungen des LindenMuseums, Stuttgart 21:97-128.

1973 Informationsverschlüsselungen im Codex Laud. Tribus, Veröffentlichungen des Linden-Museums, Stuttgart 22:95-166

1975 Weiteres zu den hinduistischen. Aquivalenzen im Codex Laud. Tribus, Veröffentlichungen des Linden-Museums, Stuttgart 24:113-136.

Brundage, Burr C.

1988 The Fifth Sun, Aztec Gods, Aztec World, University of Texas Press.

Catálogo Tula

1988 Véase Fuente, Beatriz de la

Códice Borbónico

1974 Facsimile Akademische Druck-und Verlagsanstalt, Graz, Austria

Códice Borgia 
1976 Facsimile Akademische Druck-und Verlagsanstalt, Graz, Austria.

Códice Laud

1966 Facsimile Akademische Druck-und Verlagsanstalt, Graz, Austria.

Códice Magliabechi

1903 The Book of Life of the Ancient Mexicans, Facsimile, Berkeley, University of California.

Códice Mendocino

1925 Fotocopia Museo Nacional, México.

Códice Vindobonensis Mexicanus I

1963 Facsimile Akademische Druck-und Verlagsanstalt, Graz, Austria

Davies, Nigel

1977 The Toltecs until the Fall of Tula, Norman, University of Oklahoma Press.

1980 The Toltec Heritage, Norman, University of Oklahoma Press

Ekholm, Gordon F.

1944 "Excavations at Tampico and Panuco in the Huasteca, Mexico", Anthropological Papers 38: Part V. American Museum of Natural History, New York.

Enciso, Jorge

1971 Designs from Pre-Columbian Mexico, New York, Dover Publications.

Franco, José Luis

1956 "Malacates del complejo Tula-Mazapan". Estudios Antropológicos, Homenaje a

Manuel Gamio, Universidad Nacional Autónoma de México, pp. 201-212.

Fuente, Beatriz de la, Silvia Trejo y Nelly Gutiérrez Solana

1988 Escultura en piedra de Tula, Universidad Nacional Autónoma de México.

García Cook, A y Leonor Merino C.

1974 "Malacates de Tlaxcala: intento de una secuencia evolutiva", Comunicaciones, proyecto Puebla- Tlaxcala, 11, Puebla, pp. 27-36.

García García, María Teresa

1987 Huexotla, un sitio del Acolhuacan, Instituto Nacional de Antropología e Historia, Col. Científica, México.

Horcasitas, Fernando, Sarah O. de Ford y Thomas Ford

1961 "Malacates del México antiguo", A William Cameron Townsend en el $25^{\circ}$ Aniversario del Instituto Linguiistico de Verano, México, pp. 137-150.

Kirchhoff, Paul et al.

1976 Historia tolteca chichimeca, Instituto Nacional de Antropología e Historia, México.

Raymond, Louis C.

1984 "Spindle Whorls in Archaeology", Katunob, Occasional Publications in Mesoamerican Anthropology, 30, Greely, Colorado, pp. 135-252.

Sahagún, Fray Bernardino de

1969 Florentine Codex, Book 6, School of American Research, Santa Fe, Transl by C.E. Dibble and A $\mathrm{O}$. Anderson.

Seler, Eduard

1963 Gesammelte Abhandlungen v. 2, Akademische Druck-und Verlagsanstalt, Graz, Austria. 
Seler-Sachs, Caecilie

1916 Die Huasteca-Sammlung des Kgl. Museums für Völkerkunde zu Berlin, BaesslerArchio v 5, Berlin, pp. 98-135.

Spranz, Bodo

1964 Göttergestalten in den Mexikanischen Handschriften der Codex Borgia Gruppe, Acta Humboldtiana, Wiesbaden.

Tezozomoc, Hernando Alvarado

1944 Crónica Mexicana, México.

Thompson, J Eric S.

1960 Maya Hieroglyphic Writing, an Introduction, Norman, University of Oklahoma Press.

1972 A Commentary on the Dresden Codex, Philadelphia.

Von Winning, Hasso

1971 "Relief-decorated pottery from Central Veracruz, México"; Addenda Ethnos 36:1-4, Stockholm, pp. 38-51.

1975 "A victim of the Planet Venus?", Masterkey 49:4, Los Angeles, pp. 124-129.

1984 Der Jaguar und sein Menschenopfer auf Reliefgefässen aus Veracruz, Tribus, Veröffentlichungen des Linden-Museums, Sttutgart 33, pp. 183-191 